\title{
Developmental Regulation of Nicotinic ACh Receptor Subunit mRNAs in the Rat Central and Peripheral Nervous Systems
}

\author{
Michele Zoli, Nicolas Le Novère, Joseph A. Hill, Jr., and Jean-Pierre Changeux \\ URA CNRS D1284, Neurobiologie Moléculaire, Institut Pasteur, Paris 75724 Cédex 15, France
}

In the present study we have investigated the anatomical distribution pattern of $\mathrm{nAChR} \alpha 3, \alpha 4, \beta 2$, and $\beta 4$ subunit mRNAs during prenatal and perinatal development of the rat CNS and PNS. Three main developmental patterns have been recognized. (1) In the majority of cases studied (caudal brain, spinal cord, dorsal root ganglia, trigeminal and geniculate ganglia) all four subunit mRNAs are initially (E11-13) detected but, during subsequent prenatal development, the level of some of these subunit mRNAs ( $\alpha 3$ and $\beta 4$ in the brain and spinal cord, $\alpha 4$ and $\beta 4$ in the dorsal root ganglia, $\alpha 4$ in the visceral sensory ganglia, and $\alpha 3$, $\alpha 4$, and $\beta 4$ in the somatic sensory ganglia) become undetectable. (2) In the case of the cerebral cortex a pair of subunit mRNAs ( $\alpha 3-\beta 2$ ) is initially (E12-13) expressed followed by a repression of the $\alpha 3$ subunit (E15) and the subsequent (E17-19) induction of the $\alpha 4$ subunit. (3) Only some subunit mRNAs are initially (E13-15) expressed in the retina ( $\alpha 3-$ $\alpha 4-(\beta 2-(34)$, parasympathetic or sympathetic motor ganglia ( $\alpha 3-\beta 2-\beta 4)$, and vestibulo-cochlear ganglia ( $\alpha 4-\beta 2)$ and their level remains stable throughout prenatal and early postnatal development.

Overall, in most central and peripheral structures the appearance of $\mathrm{nAChR}$ subunit mRNAs is precocious and temporally related to the timing of neuronal differentiation. In addition, in several structures the expression of certain subunits ( $\alpha 3, \alpha 4$ or $\beta 4$ ) is transient, although not $\beta 2$. Finally, the comparison of the different regional distribution patterns suggests that a limited number of structure-specific receptor isoforms are functional during development of CNS and PNS.

[Key words: neuronal nicotinic ACh receptor, development, brain, ganglia, rat, oligodeoxynucleotides]

The neuronal nicotinic acetylcholine receptor (nAChR) belongs to the superfamily of ligand-gated ion channels (Cockcroft et al., 1992; Galzi et al., 1992) largely responsible for fast responses to neurotransmitters. Molecular cloning methods have revealed the existence of homologous genes encoding $\mathrm{nAChR}$

\footnotetext{
Received Jan. 13, 1994; revised Aug. 26, 1994; accepted Sept. 7, 1994

This work was supported by the Centre National de la Recherche Scientifique, the Collège de France, the Institut National de la Santé et de la Recherche Médicale (Contract 872004), the E.C. Biomed Program (Contract CT94-1060), and the Direction des Recherches et Etudes Techniques (Contract 90/142). Support from postdoctoral fellowships awarded by the European Molecular Biology Organization and the Fyssen Foundation (M.7.) is acknowledged. We are grateful to Dr. M. Picciotto for critical reading of the manuscript.

Correspondence should be addressed to Dr. Jean-Pierre Changeux, Neurobiologie Moléculaire, Institut Pasteur, 25 Rue du Docteur Roux, 75724 Paris Cédex 15, France.

Copyright (C) 1995 Society for Neuroscience $0270-6474 / 95 / 151912-28 \$ 05.00 / 0$
}

subunits which have been named $\alpha 2-8$, if carrying a pair of cysteines shown to contribute to the ACh binding site, or $\beta 2-4$ (Sargent, 1993).

The functional neuronal $n A C h R$ results from the assembly of $\alpha$ - and $\beta$-chains, with a putative stoichiometry of $2(\alpha): 3(\beta)$ (Anand et al., 1991; Cooper et al., 1991). Heterologous expression studies in Xenopus oocytes and in mouse fibroblasts, as well as patch-clamp studies in brain and ganglionic preparations suggest that multiple subunit combinations may assemble to form functional $\mathrm{nAChRs}$ with distinct pharmacological specificities and ionic channel properties (e.g., Listerud et al., 1991; Luetje and Patrick, 1991; Mulle et al., 1991). Accordingly, several different combinations of $n A C h R$ subunit mRNAs and/or proteins have been identified in central and peripheral nervous structures (Role, 1992).

The regulation of $\mathrm{nAChR}$ gene expression during development remains largely unexplored. In skeletal muscle (reviewed in Salpeter and Loring, 1985; Changeux, 1991), nAChR subunit mRNAs and binding sites appear at the myoblast stage and progressively increase during the formation of myotubes. Upon the arrival of cholinergic motor nerve endings, local clustering, accumulation, and metabolic stabilization of nAChRs occur in the junctional membrane accompanied by a decrease of nAChRs in extrajunctional areas. In some species, a switch in the composition of the receptor (from $\gamma$ to $\epsilon$ subunit) occurs at around the time of birth (Brehm and Henderson, 1988).

Less is known about developmental changes in neuronal nAChRs, especially in mammals. In mammalian CNS, studies have mainly focussed on the development of nicotinic binding in the postnatal period (see, e.g., Fiedler et al., 1987; Semba, 1992). In the chick lateral spiriform nuclcus, the onset of $\alpha 2$ subunit mRNA expression coincides with cholinergic innervation (Daubas et al., 1990). In the chick optic lobe, a transient increase in $\beta 2$ transcript expression occurs upon arrival of the retinal afferents (Matter et al., 1990).

In the embryonic chick ciliary ganglion, the formation of mature synaptic contacts is paralleled by a progressive increase in several $\mathrm{nAChR}$ subunit mRNAs, ACh response and density of nicotinic binding sites (Margiotta and Gurantz, 1989). However, no developmental switch in subunit composition was detccted (Corriveau and Berg, 1993). In chick sympathetic ganglia, an increased sensitivity to ACh accompanies the embryonic increase in the number of synaptic boutons (Role 1988; Moss et al., 1989). These data raise the possibility that, in these systems, innervation directly stimulates neuronal $\mathrm{nAChR}$ gene expression.

Given the complexity and heterogeneity of the CNS, it appears relevant to assess the region-specific pattern of develop- 

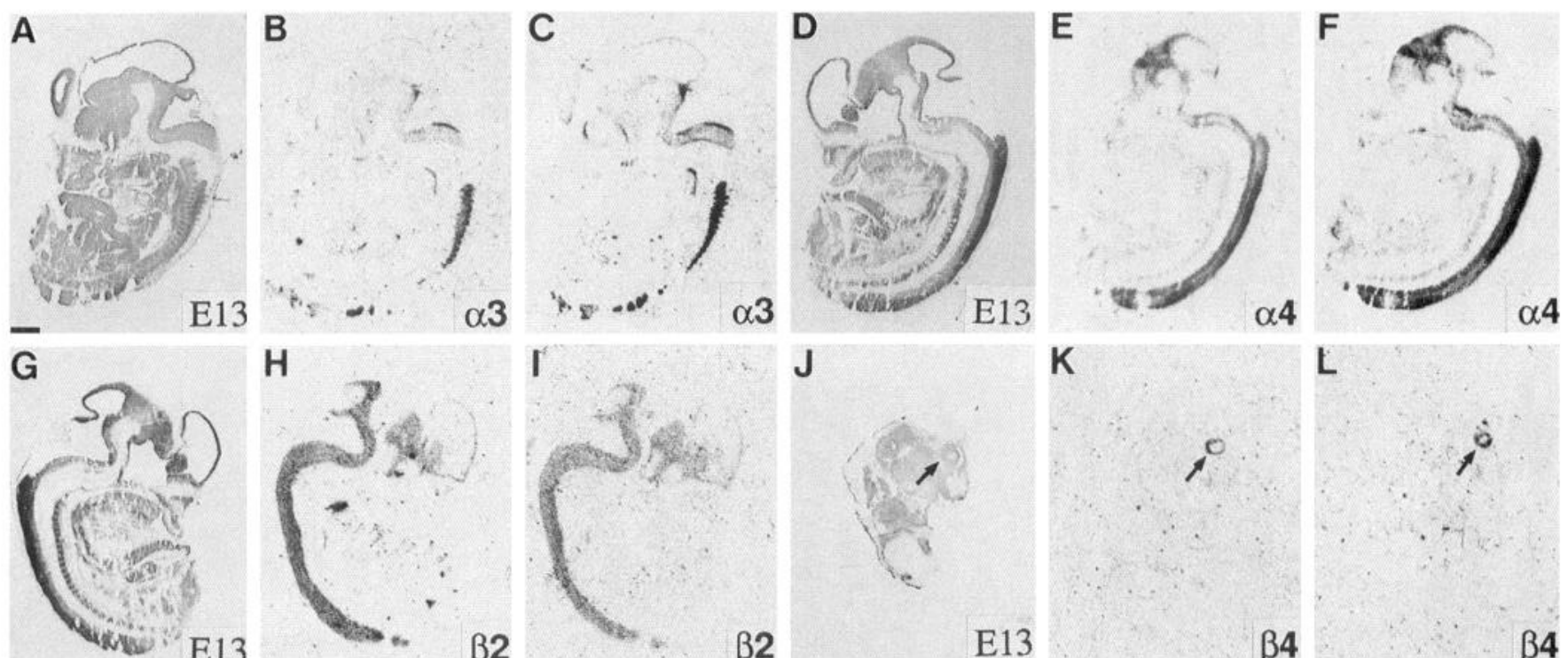

K
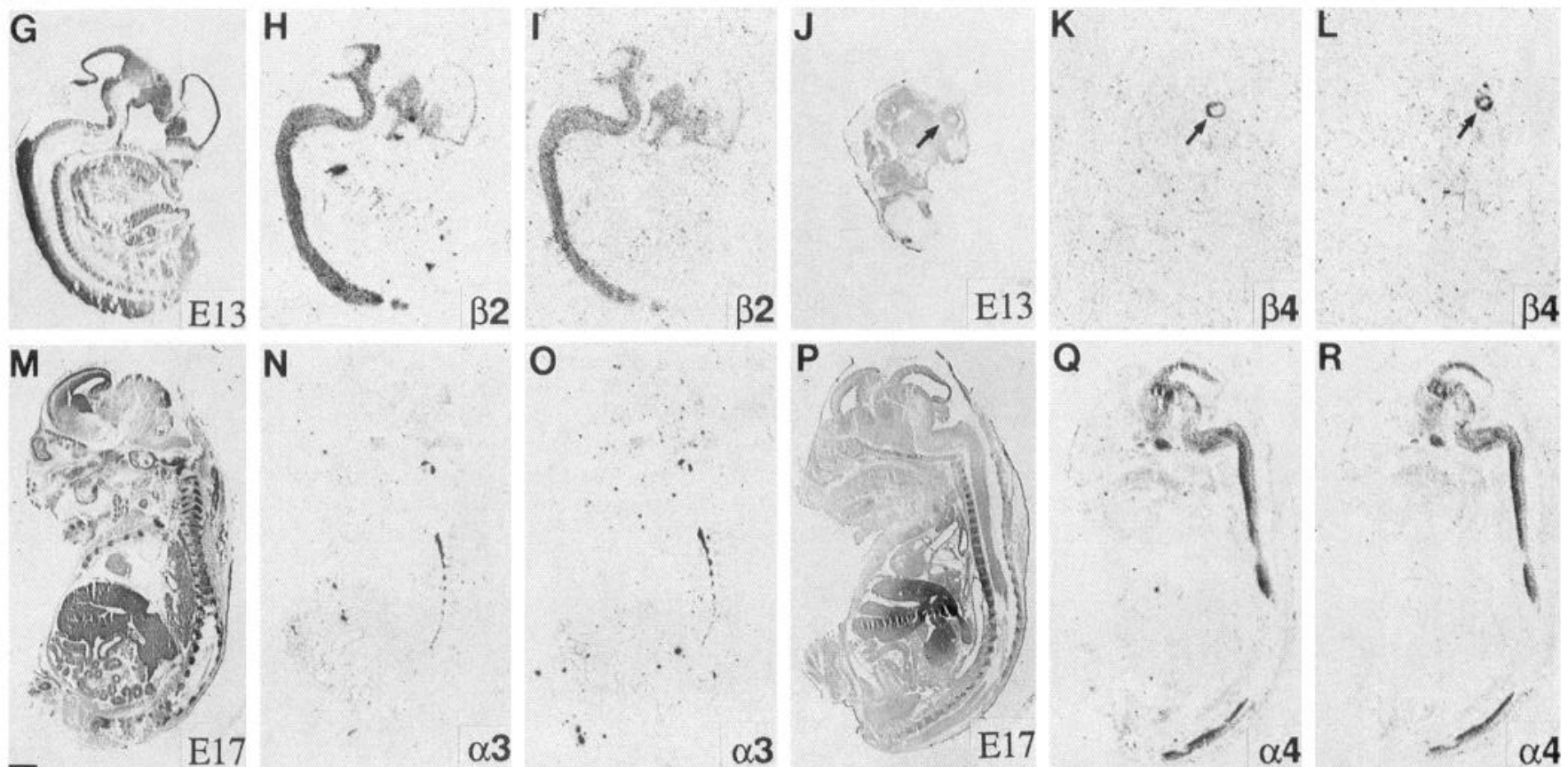

E13

B4

$\beta 4$
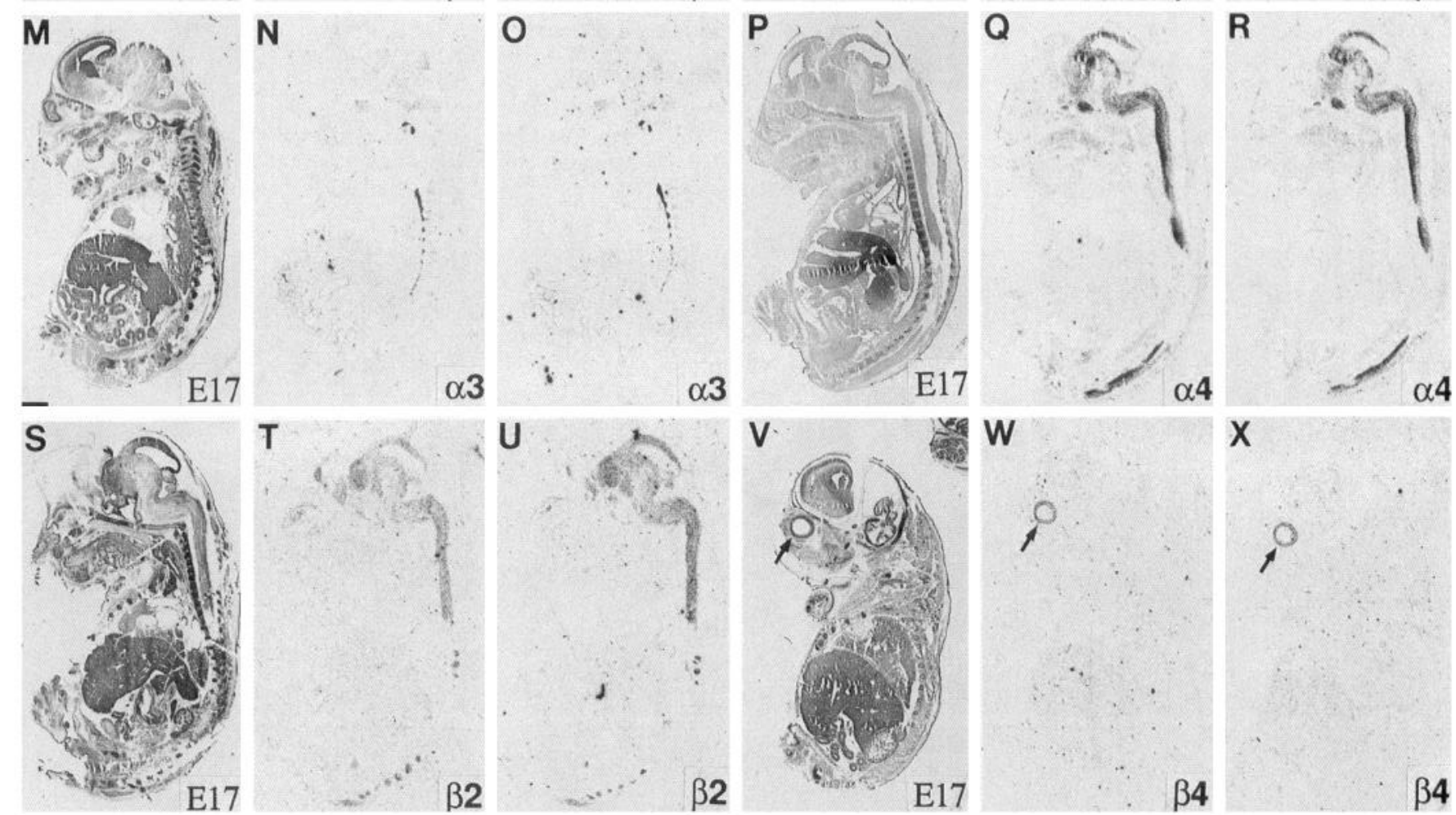

W

$\mathrm{X}$
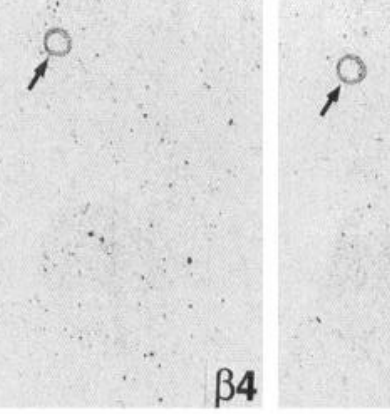

Figure 1. Bright-field microphotographs of film autoradiograms showing hybridization with different oligonucleotide probes against $\mathrm{nAChR}$ subunit mRNAs in sagittal sections of E13 $(A-L)$ and E17 $(M-X)$ rat embryos. The nAChR subunit mRNA labeled is indicated in each panel. $B$ and $C, \alpha 3 \mathrm{nAChR}$ subunit mRNA labeled by oligonucleotide $46(B)$ or $31(C)$. $E$ and $F, \alpha 4$ nAChR subunit mRNA labeled by oligonucleotide 47 $(E)$ or $49(F) . H$ and $I, \beta 2$ nAChR subunit mRNA labeled by oligonucleotide $37(H)$ or $51(I) . K$ and $L, \beta 4$ nAChR subunit mRNA labeled by oligonucleotide $61(K)$ or $62(L)$; the arrow points to the retina. $N$ and $O, \alpha 3$ nAChR subunit mRNA labeled by oligonucleotide $109(N)$ or 110 $(O) . Q$ and $R, \alpha 4 \mathrm{nAChR}$ subunit mRNA labeled by oligonucleotide $49(Q)$ or $47(R) . T$ and $U, \beta 2 \mathrm{nAChR}$ subunit mRNA labeled by oligonucleotide $51(T)$ or $37(U)$. W and $X, \beta 4$ nAChR subunit mRNA labeled by oligonucleotide $62(W)$ or $61(X)$; the arrow points to the retina. Scale bars: $A-$ $L, 1 \mathrm{~mm} ; M-X, 2 \mathrm{~mm}$.

mental expression of the different nAChR subunit mRNAs. Here we report extensive in situ hybridization observations on the evolution of $\alpha 3, \alpha 4, \beta 2$, and $\beta 4 \mathrm{nAChR}$ subunit mRNAs in the rat CNS and several peripheral structures during prenatal and early postnatal development. These subunits are thought to form the predominant $\mathrm{nAChR}$ isoforms in the ganglia ( $\alpha 3$ and $\beta 4$,
Halvorsen and Berg, 1990; Listerud et al., 1991) and CNS ( $\alpha 4$ and $\beta 2$, Whiting et al., 1991; Flores et al., 1992).

\section{Materials and Methods}

Oligodeoxynucleotide synthesis and labeling. Following analysis for mRNA secondary structure using GCG SEQUENCE ANALYSIS SOFTWARE 


\begin{tabular}{|c|c|c|c|c|}
\hline Subunit & Code & Sequence & Length & GC\% \\
\hline$\alpha 3$ & 31 & 889-931 & 43 & 53 \\
\hline$\alpha 3$ & 46 & $987-1031$ & 45 & 62 \\
\hline$\alpha 3$ & 109 & $64-108$ & 45 & 51 \\
\hline$\alpha 3$ & 110 & $472-516$ & 45 & 58 \\
\hline$\alpha 4$ & 47 & $1511-1555$ & 45 & 62 \\
\hline$\alpha 4$ & 49 & $1270-1314$ & 45 & 55 \\
\hline$\beta 2$ & 37 & $1276-1320$ & 45 & 60 \\
\hline$\beta 2$ & 51 & $1136-1180$ & 45 & 55 \\
\hline$\beta 4$ & 61 & $1083-1127$ & 45 & 55 \\
\hline$\beta 4$ & 62 & $1322-1366$ & 45 & 53 \\
\hline ChAT & 67 & $1756-1800$ & 45 & 53 \\
\hline ChAT & 68 & $1827-1871$ & 45 & 56 \\
\hline
\end{tabular}

cDNA sequences were taken from the following sources: $\alpha 3$, Boulter et al., 1986; $\alpha 4$, Goldman et al., 1987; $\beta 2$, Deneris et al., 1988; $\beta 4$, Duvoisin et al., 1989; ChAT, Ishii et al., 1990.

7.1 , oligodeoxynucleotide sequences were chosen in unique regions of the mRNAs and synthesized using a Cyclone (Biosearch Inc.) DNA synthesizer. The probe characteristics are reported in Table 1. The oligonucleotide probes were labeled at the $3^{\prime}$ end using ${ }^{35} \mathrm{~S}$-dATP (Amersham) and terminal deoxynucleotidyl transferase (Boehringer-Mannheim) following the specifications of the manufacturer to a specific activity of $100-300 \mathrm{kBcq} / \mathrm{pmol}$. The labeled probes were separated from unincorporated ${ }^{35} \mathrm{~S}$-dATP by means of NucTrap push columns (Stratagene, La Jolla, CA), precipitated in ethanol, and resuspended in distilled water containing $50 \mathrm{~mm}$ dithiothreitol.

Animals. Sprague-Dawley rats (Iffacredo, Lyon) were used. Several embryonic and postnatal ages were examined: E10, E11, E12, E13, E15, E17, E19, P0, P4, and adult. Embryos were dated according to Paxinos et al. (1991) so that E0 corresponds to the $24 \mathrm{hr}$ following pairing and $\mathrm{P} 0$ to the $24 \mathrm{hr}$ following birth. For each developmental time two to five animals were used. In the case of early embryos (E11-E15), which have abrupt changes in nAChR mRNA levels, at least four animals/ group were analyzed. Tissues from embryos (obtained from ether-anesthetized timed-pregnant rats) and postnatal rats (killed by decapitation) were fresh frozen on dry ice.

In situ hybridization procedure. Frozen tissues were cut at the cryostat (14 $\mu \mathrm{m}$ thick sections), thaw mounted on poly-L-lysine coated slides and stored at $-80^{\circ} \mathrm{C}$ for $1-3 \mathrm{~d}$. The procedure was carried out according to Young et al. (1986). Briefly, sections were fixed with $4 \%$ paraformaldehyde for $5 \mathrm{~min}$ at room temperature, washed in phosphate buffered saline (PBS) and then acetylated and delipidated in ethanol and chloroform $(5 \mathrm{~min})$. They were prehybridized for $2-4 \mathrm{hr}$ at $37^{\circ} \mathrm{C}$ and hybridized for $20 \mathrm{hr}$ at $37^{\circ} \mathrm{C}$ under parafilm coverslips. The composition of the prehybridization and hybridization mixtures was $50 \%$ formamide, $0.6 \mathrm{M} \mathrm{NaCl}, 0.1 \mathrm{M}$ dithiothreitol, $10 \%$ dextran sulfate, 1 mM ethylenediaminetetraacetic acid (EDTA), $1 \times$ Denhardt's solution $(50 \times=1 \%$ bovine serum albumin, $1 \%$ Ficoll, $1 \%$ polyvinylpyrrolidone), $0.1 \mathrm{mg} / \mathrm{ml}$ polyA (Boehringer), $0.5 \mathrm{mg} / \mathrm{ml}$ yeast tRNA (Sigma), $0.05 \mathrm{mg} / \mathrm{ml}$ herring sperm DNA (Promega) in $0.02 \mathrm{M}$ Tris- $\mathrm{HCl}, \mathrm{pH} 7.5$. Probes were applied at a concentration of $2000-3000 \mathrm{Bcq} / 30 \mu \mathrm{l} / \mathrm{section}$ (corresponding to around $15 \mathrm{fmol} / \mathrm{section}$ ). After removal of coverslips and initial rinse in $2 \times$ standard saline citrate (SSC) solution $(3 \mathrm{M} \mathrm{NaCl}$,
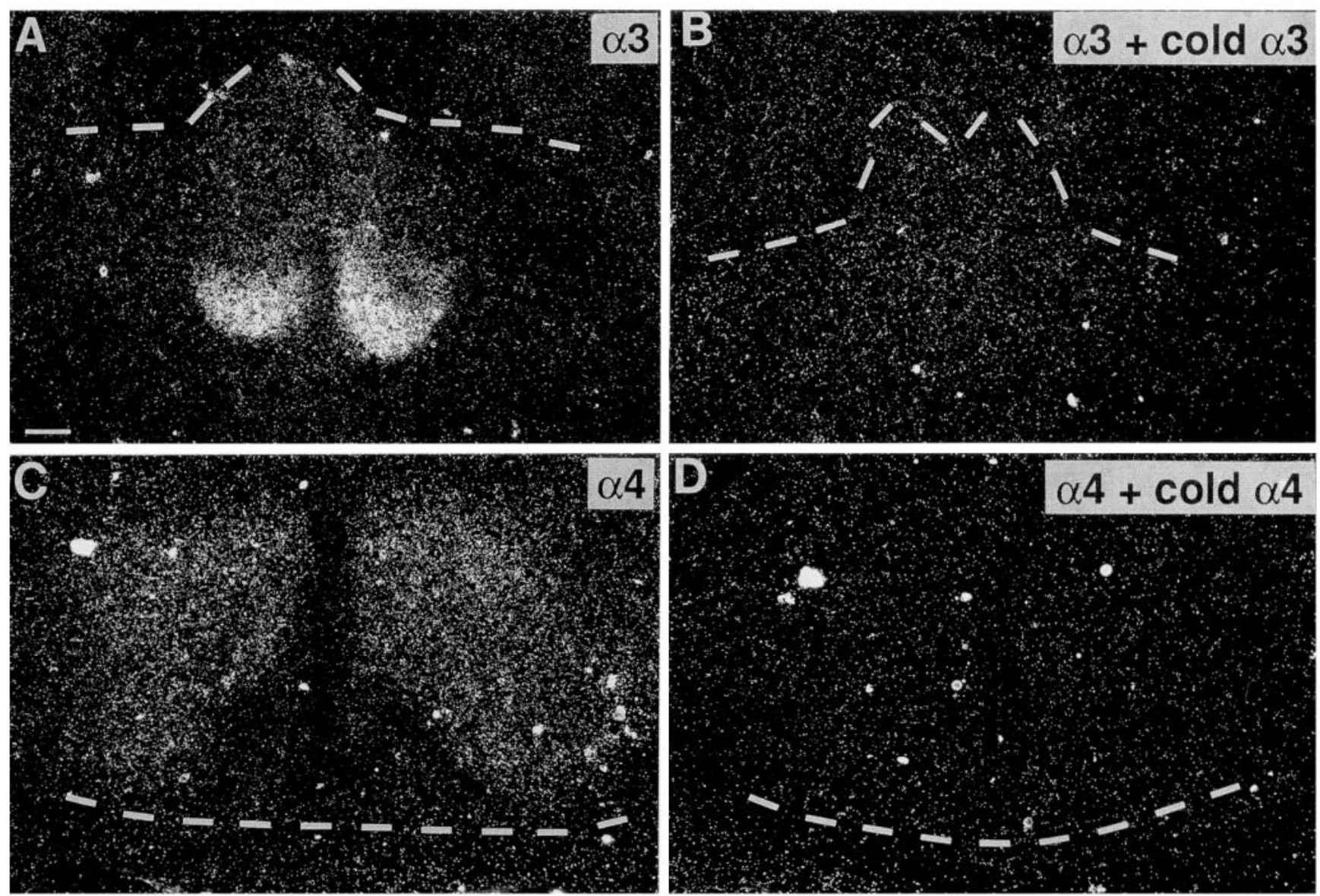

Figure 2. Dark-field microphotographs of emulsion autoradiograms showing $\alpha 3 \mathrm{nAChR}$ subunit mRNA in coronal sections of the lateral habenula of E17 rat embryo $(A$ and $B)$ and $\alpha 4 \mathrm{nAChR}$ mRNA in coronal sections of the ventromedial hypothalamic nucleus of a E19 rat embryo ( $C$ and $D$ ). In $B$ and $D$, sections hybridized with a 20 -fold excess of cold probe are shown. The dashed lines outline the borders of the brain. Scale bar, $100 \mu \mathrm{m}$. 
Table 2. Development of nAChR subunit mRNAs in the brain

$\alpha 3$

E11

Telencephalon

Diencephalon

Mesencephalon

Rhombencephalon

E12

Telencephalon

Ventral part

Dorsal part

Diencephalon

Ventral part

Dorsal part

Meso-diencephalic junction

Mesencephalon

Ventral part

Dorsal part

Isthmus region

Metencephalon ${ }^{a}$

Medioventral part

Lateral part

Mediodorsal part

Myelencephalon $^{h}$

Medioventral part

Lateral part

Mediodorsal part

Caudal part

E13

Telencephalon

Cerebral cortex

External part

Internal part

Hippocampal formation

Septum

Basal ganglia

Forebrain nic

Preoptic area

Diencephalon

Ventral part

Dorsal part

Mesodiencephalic junction

Mesencephalon

Ventral part

Dorsal part

Isthmus region

Metencephalon $^{a}$

Medioventral part

Lateral part

Mediodorsal part

Myelencephalon ${ }^{b}$

Medioventral part

Lateral part

Mediodorsal part

Caudal part

E15

Telencephalon

Cerebral cortex

Plate

Intermediate layers

Neuroepithelium

$-$

$+$

$-$

$-$

$+$

$+$

$+$

$-$

$-$

$-$

$+$

$-$ $\alpha 4$

$\beta 2$

$\beta 4$

$\begin{array}{ll}- & - \\ - & - \\ -1+ & -1+ \\ -1+ & -1+\end{array}$

$-$

$-1+$

$-1+$

$-1+$

$-1+$

$-1+$

$-1+$

$-$

$-1++$

$-$

$-\quad-1+$

$++$

$-$

$++$

$++$

$++$

$+$

$++$

$-1+$

$++$

$++$

$++$

$-$

$++$

$++$

$+++$

$+++$

$++$

$-$

$+++$

$-1++\quad-$

$-$

$++\quad-$

$++\quad-1+$

$+\quad-$

$++$

$++\quad-$

$++\quad-1++$

$-$

$+++$

$++++$

$-\quad-$

$++++$

$-1+$

$-1+$

$-1++$

$++$

$++$

$-1+$

$+1++$

$++1++$

$-$

$+1++$

$+\mathrm{I}++$

$++1++$

$-$

$++1+++$

$++$

$-1+$

$-1+$

-

$-1+$

$-1+$

-

$-$

$-$

$-1+$

$-$

$-$

$++$

-

$-$

$-$

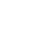

++
+++

++
+
+

$$
\text { (1+ }
$$

列


Table 2. Continued

\begin{tabular}{|c|c|c|c|c|}
\hline & $\alpha 3$ & $\alpha 4$ & $\beta 2$ & $\beta 4$ \\
\hline Hippocampal formation & - & + & + & - \\
\hline Septum & - & + & +++ & - \\
\hline Basal ganglia & - & - & +++ & - \\
\hline Forebrain ni ${ }^{c}$ & - & - & +++ & - \\
\hline Preoptic area & + & + & +++ & - \\
\hline \multicolumn{5}{|l|}{ Diencephalon } \\
\hline \multicolumn{5}{|l|}{ Thalamus } \\
\hline Habenula & ++ & + & +++ & +++ \\
\hline Anterior & - & + & +++ & - \\
\hline Intermediate & - & + & +++ & - \\
\hline Posterior & - & ++ & +++ & - \\
\hline \multicolumn{5}{|l|}{ Hypothalamus } \\
\hline Anterior & + & $+/++$ & +++ & - \\
\hline Posterior & + & $+1++$ & +++ & - \\
\hline Mammillary area & + & + & ++ & + \\
\hline \multicolumn{5}{|l|}{ Mesencephalon } \\
\hline Ventral & + & ++ & +++ & $-1+$ \\
\hline Dorsal & - & + & ++ & - \\
\hline \multicolumn{5}{|l|}{ Metencephalon } \\
\hline Ventral cochlear nu & ++ & + & +++ & - \\
\hline Motor nu 5 & + & + & +++ & - \\
\hline Other pontine ni & + & $+/++$ & +++ & - \\
\hline Cerehellar neurnepithelium & ++ & - & - & ++ \\
\hline \multicolumn{5}{|l|}{ Myelencephalon } \\
\hline Motor ni & + & + & +++ & - \\
\hline Other bulbar ni & + & $+/++$ & +++ & - \\
\hline \multicolumn{5}{|l|}{ E17 } \\
\hline \multicolumn{5}{|l|}{ Telencephalon } \\
\hline \multicolumn{5}{|l|}{ Cerebral cortex } \\
\hline Plate & - & - & ++ & - \\
\hline Subplate & - & + & + & - \\
\hline Intermediate layer & - & - & + & - \\
\hline Subventricular layer & - & - & + & - \\
\hline Neuroepithelium & - & - & - & - \\
\hline Claustrum & - & ++ & ++ & - \\
\hline Olfactory bulb & - & - & ++ & - \\
\hline Primary olfactory cortex & - & + & ++ & - \\
\hline Hippocampal formation & - & + & ++ & - \\
\hline Septum & - & + & ++ & - \\
\hline Basal ganglia & - & - & ++ & - \\
\hline Basal forebrain ni & - & + & ++ & - \\
\hline Dorsomedial forebrain ni & - & + & ++ & - \\
\hline Preoptic area & - & + & ++ & - \\
\hline \multicolumn{5}{|l|}{ Amygdala } \\
\hline Medial & - & + & ++ & - \\
\hline Other ni & - & - & ++ & - \\
\hline \multicolumn{5}{|l|}{ Diencephalon } \\
\hline Pineal gland & - & - & - & + \\
\hline \multicolumn{5}{|l|}{ Thalamus } \\
\hline Medial habenula & +++ & + & + & +++ \\
\hline Anterior group ni & - & + & ++ & - \\
\hline Mediodorsal nu & - & + & ++ & - \\
\hline Intralaminar group $\mathrm{ni}$ & - & + & ++ & - \\
\hline Midline group ni & - & + & ++ & - \\
\hline Lat geniculate dorsal & - & ++ & ++ & - \\
\hline Lat geniculate ventral & - & + & ++ & - \\
\hline Med geniculate & - & + & ++ & - \\
\hline Other ni & - & ++ & ++ & - \\
\hline
\end{tabular}


Table 2. Continued

$\alpha 3$

Hypothalamus
Anterobasal area
Ventromedial nu
Arcuate nu
Lat mammillary area
Other ni

Brainstem

Superior colliculus External layers Internal layers

Pretectum

Central grey

Locus coeruleus

Cranial nerve motor ni

Ventral cochlear nu

Other ni

Cerebellum

Neuroepithelium

Purkinje cell layer

Deep ni

E19

Telencephalon

Cerebral cortex

Plate

Subplate

Intermediate layer

Subventricular layer

Neuroepithelium

Claustrum

Olfactory bulb

Primary olfactory cortex

Hippocampal formation

Pyramidal layer

Other layers

Septum

Basal ganglia

Basal forebrain ni

Dorsomedial forebrain ni

Preoptic area

Amygdala

Diencephalon

Pineal gland

Thalamus

Medial habenula

Anterior group ni

Mediodorsal nu

Intralaminar group ni

Midline group ni

Ventral group ni

Lat geniculate dorsal

Lat geniculate ventral

Med geniculate

Other ni

Zona incerta

Hypothalamus

Anterior ni

Ventromedial nu

Arcuale nu

Lat mammillary ni

Med mammillary ni

Other ni $\alpha 4$

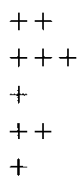

$+$

\section{$+$}

$++$

$++$

$++$

$++$

$+$

$++$

$+$

$-$

$+$

$++$ $\beta 2$

$\begin{array}{ll}++ & - \\ ++ & - \\ ++ & - \\ ++ & - \\ + & -\end{array}$

$\begin{array}{ll}++ & - \\ ++ & - \\ ++ & - \\ ++ & - \\ ++ & - \\ +++ & - \\ ++ & + \\ ++ & - \\ & \\ - & + \\ ++ & - \\ ++ & -\end{array}$

$-$

$$
+
$$

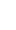

$+\quad++$

$++\quad+$

- + +

- +

$\begin{array}{lll}- & - & -\end{array}$

$++\quad++$

$\begin{array}{lll}+ & + & - \\ + & -\end{array}$

$+\quad++$

$+\quad++$

- +

-

- +

$+$

$+$

$-$

$-$

$-$

$-$

$-$

$-$

$-$

$++$

$\begin{array}{cccc}+++ & ++ & ++ & +++ \\ - & + & ++ & -\end{array}$

$+$

$+$

$+$

$+$

$++$

$+$

$+$

$+$

$++$

$++$

$++$

$+t$

$-$

$++$

$+$

$+$ 


\section{Table 2. Continued}

Brainstem

Superior colliculus

External layers

Internal layers

Pretectum

Substantia nigra/VTA

Central grey

Red nu

Cranial nerve motor $\mathrm{ni}$

Locus coeruleus

Ventral cochlear nu

Prepositus hypoglossal nu

Inferior olive

Other ni

Cerebellum

External germinal layer

Purkinje cell layer

Deep ni

P0

Telencephalon

Cerebral cortex

Plate

Subplate

Claustrum

Endopiriform nu

Olfactory bulb

Glomerular layer

Ext plexiform layer

Mitral cell layer

Int plexiform layer

Anterior olfactory nu

Primary olfactory cortex

Olfactory tubercle

Hippocampal gyrus Pyramidal layer

Other layers

Dentate gyrus

Granular layer

Other layers

Subiculum

Entorhinal cortex

Septum

Basal ganglia

Caudate putamen

Accumbens nu

Globus pallidus

Basal forebrain ni

Dorsomedial forebrain ni

Preoptic area

Amygdala

Diencephalon

Pineal gland

Thalamus

Medial habenula

Lateral habenula

Anterior group ni

Mediodorsal nu

Midline group ni

Paraventricular nu

Centromedian nu

Posterior nu $\alpha 3$

$\alpha 4$

$\beta 2$

$\begin{array}{ll}- & + \\ - & + \\ - & + \\ - & + \\ - & + \\ - & + \\ - & + \\ - & + \\ + & + \\ - & + \\ - & + \\ - & + \\ & - \\ + & + \\ - & + \\ - & +\end{array}$

$\begin{array}{ll}++ & - \\ ++ & - \\ ++ & - \\ ++ & - \\ ++ & - \\ ++ & - \\ +++ & - \\ ++ & - \\ +++ & + \\ ++ & - \\ ++ & - \\ ++ & - \\ & \\ - & \\ ++ & - \\ ++ & -\end{array}$

$\begin{array}{ll}++ & - \\ ++ & - \\ ++ & - \\ ++ & - \\ & \\ + & - \\ + & - \\ +++ & - \\ + & - \\ ++ & - \\ ++ & - \\ ++ & - \\ ++ & - \\ + & - \\ + & - \\ ++ & - \\ + & - \\ ++ & - \\ ++ & - \\ ++ & - \\ ++ & - \\ ++ & - \\ ++ & - \\ ++ & - \\ ++ & - \\ ++ & - \\ ++ & - \\ ++ & - \\ ++ & - \\ ++ & \end{array}$


Table 2. Continued

\begin{tabular}{|c|c|c|c|c|}
\hline & $\alpha 3$ & $\alpha 4$ & $\beta 2$ & $\beta 4$ \\
\hline Ventral group ni & - & +++ & +++ & - \\
\hline Lat geniculate dorsal & - & ++ & ++ & - \\
\hline Lat geniculate ventral & - & + & ++ & - \\
\hline Med geniculate & - & + & ++ & - \\
\hline Other ni & & +1 & +1 & $\cdots$ \\
\hline Zona incerta & - & ++ & + & - \\
\hline \multicolumn{5}{|l|}{ Hypothalamus } \\
\hline Arcuate nu & - & - & ++ & - \\
\hline Ventromedial nu & - & +++ & ++ & - \\
\hline Dorsomedial nu & - & + & ++ & - \\
\hline Lat mammillary ni & - & + & ++ & - \\
\hline Med mammillary ni & - & - & ++ & - \\
\hline Other ni & - & + & + & - \\
\hline \multicolumn{5}{|l|}{ Mesencephalon } \\
\hline \multicolumn{5}{|l|}{ Superior colliculus } \\
\hline External layers & - & + & ++ & - \\
\hline Internal layers & - & ++ & ++ & - \\
\hline Pretectum & - & ++ & ++ & - \\
\hline Substantia nigra/VTA & - & ++ & + & - \\
\hline Red nu & - & ++ & + & - \\
\hline Other ni & - & + & + & - \\
\hline \multicolumn{5}{|l|}{ Pons } \\
\hline Cranial nerve motor ni & - & + & ++ & - \\
\hline Pontine ni & - & + & ++ & - \\
\hline Ventral nu lat lemniscus & - & + & $+t$ & - \\
\hline Locus coeruleus & - & ++ & ++ & - \\
\hline Ventral cochlear nu & + & ++ & ++ & + \\
\hline Vestibula ni & - & ++ & + & - \\
\hline Other ni & - & + & + & - \\
\hline \multicolumn{5}{|l|}{ Medulla oblongata } \\
\hline 12 nerve motor nu & - & ++ & + & - \\
\hline Inferior olive & - & ++ & ++ & - \\
\hline Prepositus hypoglossal nu & - & ++ & + & - \\
\hline Other ni & - & + & + & - \\
\hline \multicolumn{5}{|l|}{ Cerebellum } \\
\hline External germinal layer & + & - & - & - \\
\hline Purkinje cell layer & - & + & ++ & - \\
\hline Deep ni & - & +++ & ++ & - \\
\hline
\end{tabular}

Scores wcre attributed as follows: + , low level; ++ , intermediate level;,+++ high level. $\Lambda t$ E1 l-12 the regions considered are often not homogeneously labeled. We therefore decided to assign the scores as follows. When the majority of the region under examination is specifically labeled, only one score is given, referring to the average intensity of specific labeling. When the specific labeling covers a lesser portion of the structure considered, two scores are given: the first one is a minus and the second one refers to the average intensity of positive clusters of cells. At E13-P0, when two scores are given, the first one refers to the average labeling in the region, and the second one to some nonidentified clusters of cells. Abbreviations: ext, external; int, internal; lat, lateral; med, medial; ne, neuroepithelium; ni, nuclei; nu, nucleus; VTA, ventral tegmental area.

"The mediodorsal part corresponds to the roof of the IV ventricle.

"The myelencephalon is subdivided into a smaller caudal part, roughly corresponding to the region caudal to the IV ventricle, and a larger rostral part, in turn composed of a medioventral, a lateral, and a mediodorsal part. This last corresponds to the roof of the IV ventricle.

- The term forebrain nuclei indicates the clusters of neurons in the subcortical forebrain which will form the basal and dorsomedial forebrain nuclei at later ages.

$0.3 \mathrm{M}$ sodium citrate) at room temperature (two times for $5 \mathrm{~min}$ ), sections were washed four times for $15 \mathrm{~min}$ in $2 \times \mathrm{SSC}, 50 \%$ formamide at $42^{\circ} \mathrm{C}$, and then two times for $30 \mathrm{~min}$ in $1 \times \mathrm{SSC}$ at room temperature; $1 \mathrm{~mm}$ dithiothreitol was added to all washing solutions. After rinsing in ice-cold distilled water and drying, they were exposed for 10-20 d to Hyperfilm- ${ }^{3} \mathrm{H}$ (Amersham) and then to a photographic emulsion (NTB2, Kodak) for 1-2 months.

Analysis of histological preparations. The analysis of the labeling pattern for the different mRNAs was carried out both on film and emul- sion autoradiograms. Identification of anatomical structures was carried out after counterstaining of the serial sections of the entire embryos with toluidine blue. Definition of anatomical areas in the brain and recognition of PNS structures was based on different atlases, including The Rat Brain in Stereotaxic Coordinates (Paxinos and Watson, 1986), the Atlas of Developing Rat Brain (Paxinos et al., 1991), the Atlas of Mouse Development (Kaufman, 1992), and the Atlas of the Prenatal Mouse Brain (Schambra et al., 1992). For cranial nerve ganglia development, the plates and descriptions from Altman and Bayer (1982) were 

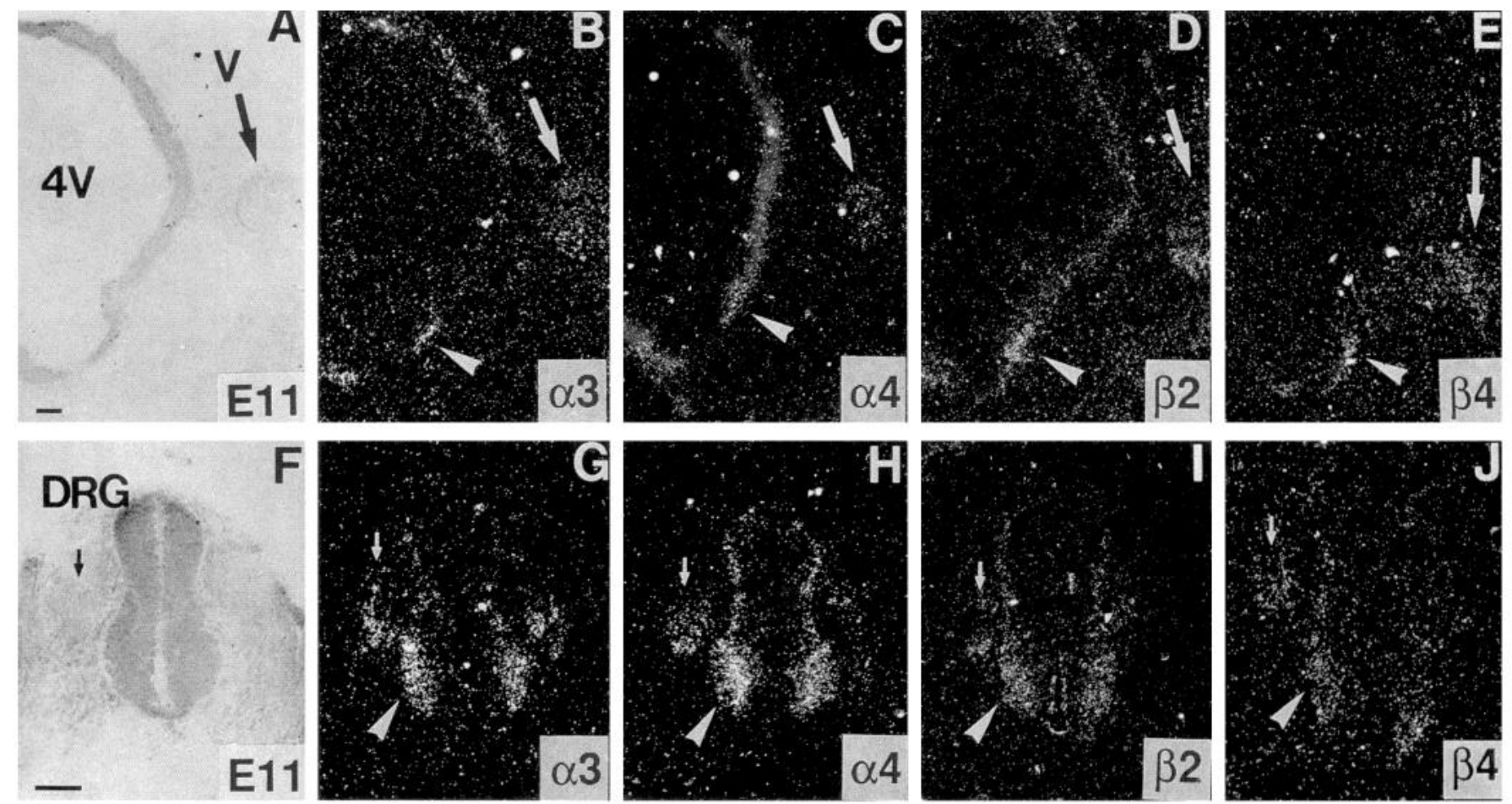

Figure 3. Dark-field microphotographs of emulsion autoradiograms showing nAChR subunit mRNAs at rhombencephalic $(A-E)$ and spinal cord $(F-J)$ levels of a E11 rat embryo. The nAChR subunit mRNA labeled is indicated in each panel. $A$ and $F$ show toluidine blue staining. In $A-E$, the arrow points to the primordium of the trigeminal ganglion $(V)$, and the arrowhead to clusters of specific grains overlain the external side of the ventral rhombencephalic neuroepithelium. In $F-J$, the arrow points to the primordium of the dorsal root ganglion $(D R G)$, and the arrowhead to the specific grains located in the ventrolateral part the spinal cord. This is the first area in the spinal cord containing differentiated neurons. $4 \mathrm{~V}$, fourth ventricle. Scale bars, $100 \mu \mathrm{m}$.

consulted. In order to confirm the identification of some central and peripheral structures (e.g., cranial nerve motor nuclei, autonomic motor ganglia) in situ hybridization for choline acetyltransferase (AChE) was performed on some sections.

A score from $1+$ (low intensity) to $3+$ (high intensity) was assigned to the labeling of the anatomical structures based on the subjective evaluation of two experimenters. Background labeling was considered the density of grains in non-neural tissues with high cellularity (such as the liver and the muscles) or with high density of extracellular matrix (such as cartilage) or the density of labeling over neural structures after displacement with $20 \times$ cold probe. In the absence of grain counting at the cellular level, the scores must be regarded with caution. For instance, decreases in labeling intensity of a developing structure may be due to dispersion of positive cells in the structure caused by multiplication of negative cells or formation of neuronal processes. Though the oligonucleotides had the same length and they were labeled according to the same protocol, no attempt to compare the signal intensity of different transcripts was made. Unless specified otherwise, the labeling shown in the pictures has been obtained by using oligonucleotides no. $31(\alpha 3), 47(\alpha 4), 51(\beta 2)$, and 62 ( $\beta 4)$ (see Table 1 for oligonucleotide characteristics).

Specificity controls. For each mRNA, two to four oligonucleotides were selected in unique parts of the sequence (e.g., the putative cytoplasmic loop between M3 and M4 for nAChR subunits). An initial assessment of specificity was performed by searching for possible homology with other known sequences in GenBank/EMBL. As histolog-
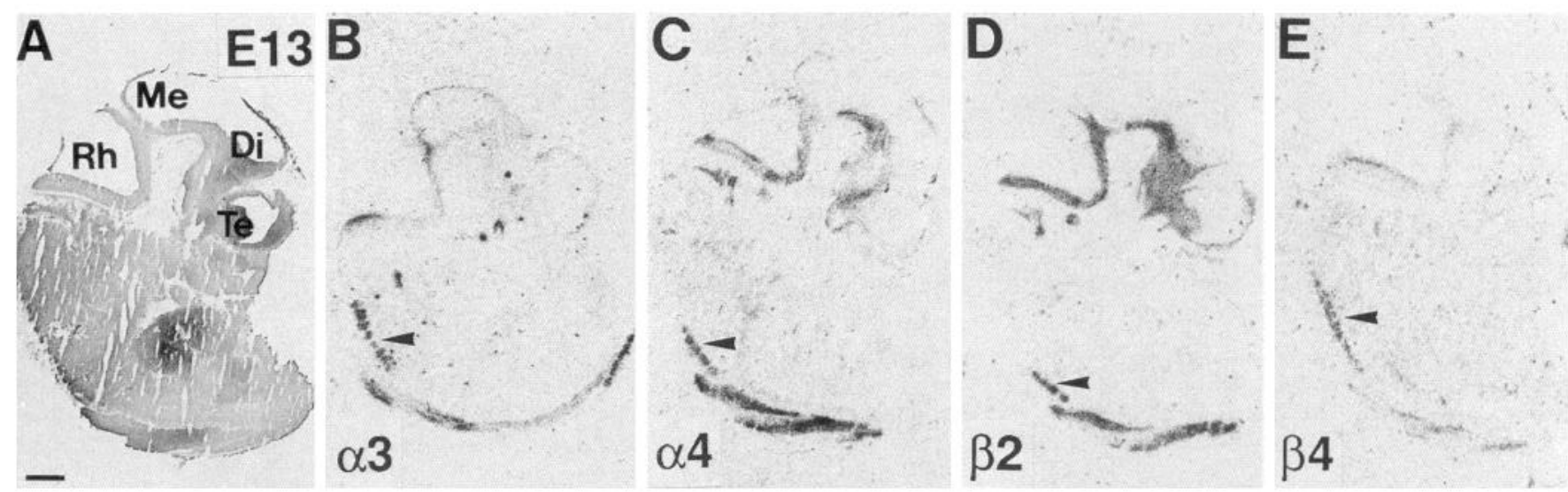

Figure 4. Bright-field microphotographs of film autoradiograms showing nAChR subunit mRNAs in sagittal sections of a E13 rat embryo. The $\mathrm{nAChR}$ subunit mRNA labeled is indicated in each panel. A shows toluidine blue staining. Arrowheads point to dorsal root ganglia. Abbreviations: $\mathrm{Di}$, diencephalon; $M e$, mesencephalon; $R h$, rhombencephalon; $T e$, telencephalon. Scale bar, $1 \mathrm{~mm}$. 

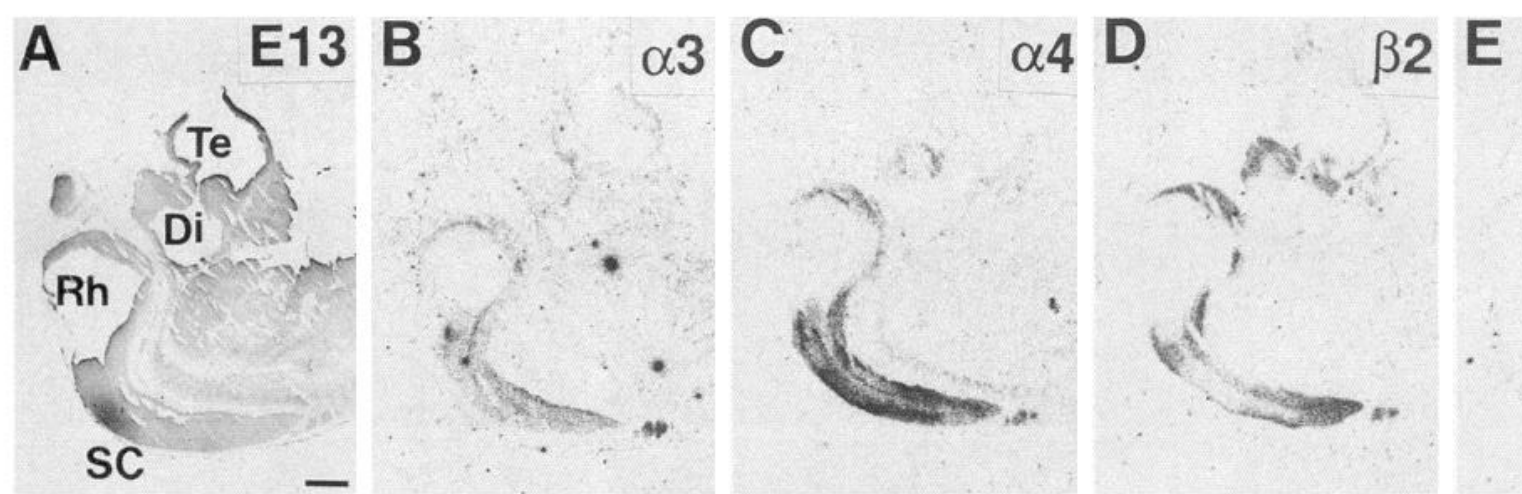

Figure 5. Bright-field microphotographs of film autoradiograms showing nAChR subunit mRNAs in sagittal sections of a E13 rat embryo. The nAChR subunit mRNA labeled is indicated in each panel. A shows toluidine blue staining. Abbreviations: $D i$, diencephalon; $R h$, rhombencephalon; $S C$, spinal cord; $T e$, telencephalon. Scale bar, $1 \mathrm{~mm}$.

ical tests for specificity we considered the following. (1) Two or more oligonucleotide probes for each mRNA gave the same hybridization pattern (Fig. 1). (2) The pattern of labeling in central structures in the adult rat was in agreement with that observed by other authors (Wada et al., 1989; Dineley-Miller and Patrick, 1992). (3) Given that most oligonucleotides used were 45 -mers with similar GC content (Table 1), each oligonucleotide probe constituted a control for the specificity of the others. (4) The addition to the hybridization mixture of a 20 -fold excess of cold probe produced a complete disappearance of the labeling (Fig. 2).

The oligonucleotide probes used fulfilled all these criteria, with the exception of the four probes against $\alpha 3$ mRNA, which did not satisfy critcrion 2 . Previous studies based on cRNA probes showed a relatively widespread distribution of this subunit mRNA in adult rats, notably high levels in the cerebral cortex layer IV, entorhinal cortex layer II, anterior and ventral thalamic nuclei, medial and lateral geniculate nuclei, medial
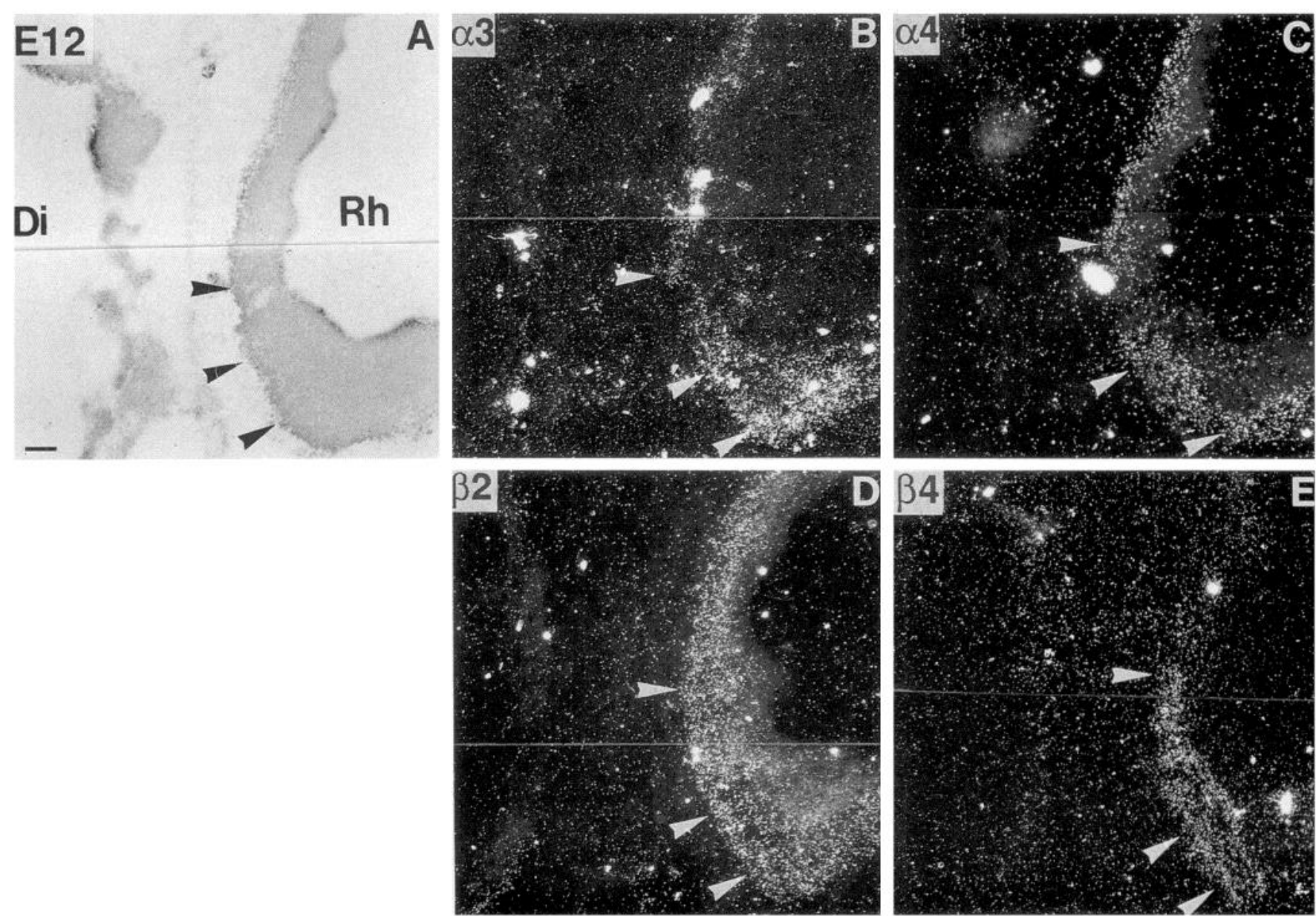

Figure 6. Dark-field microphotographs of emulsion autoradiograms showing nAChR subunit mRNAs in sagittal sections of the rostral rhombencephalon $(R h)$ and caudal diencephalon $(D i)$ of a E12 rat embryo. The nAChR subunit mRNA labeled is indicated in each panel. A shows toluidine blue staining. Arrowheads point to the external side of the lateral metencephalon, indicating a similar distribution of the four transcripts in this region. Scale bar, $100 \mu \mathrm{m}$. 

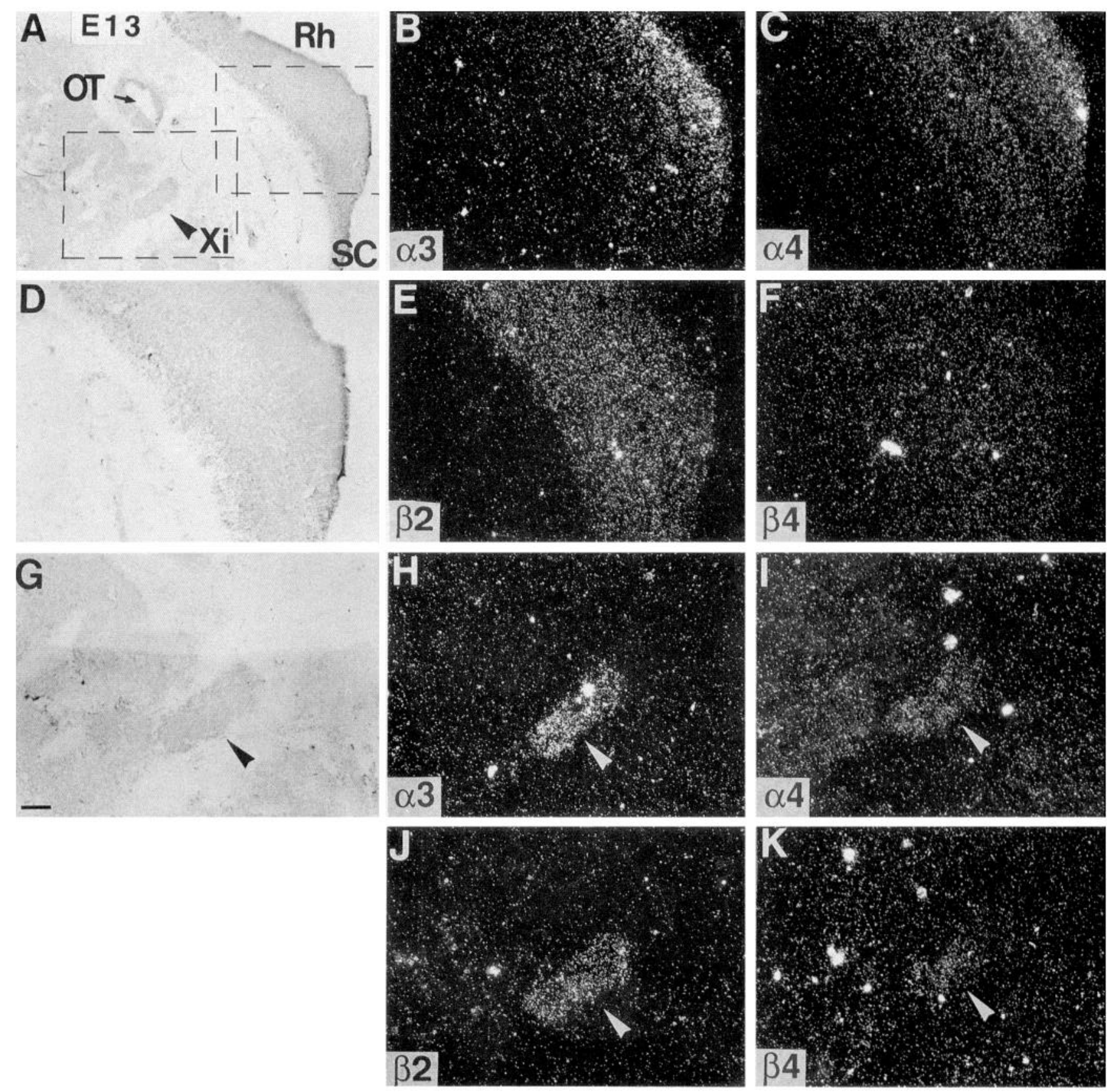

Figure 7. Dark-field microphotographs of emulsion autoradiograms showing nAChR subunit mRNAs in sagittal sections of the caudal rhombencephalon $(R h, B-F)$ and inferior X ganglion $(X i, G-K)$ of a E13 rat embryo. The nAChR subunit mRNA labeled is indicated in each panel. $A, D$, and $G$ show toluidine blue staining. In $A$ the rectangular frames delineate the areas which are magnified in the other panels. In $A$ and $G-K$, the arrowhead points to the Xi. Abbreviations: $O T$, otic vesicle; $S C$, spinal cord. Scale bar, $100 \mu \mathrm{m}$.

habenula, posterior hypothalamus and supramammillary nuclei, pineal gland, motor nuclei of the V and VII nerves, locus coeruleus, nucleus ambiguus, and area postrema (Wada et al., 1989). At variance with these observations, in adult rats we could detect high levels of $\alpha 3$ mRNA signal only in the medial habenula, intermediate in the pineal gland, area postrema, motor nucleus of the $\mathrm{V}$ nerve and cerebellum, low in a few thalamic nuclei and locus coeruleus. Part of the discrepancy may be ascribed to a lower sensitivity of oligonucleotide probes versus riboprobes. However, considering the difficulty of carrying out specificity controls for cRNA probes, especially when hydrolysis of the probe is performed in the histological procedure (Wada et al., 1989), it is possible that some labeling previously attributed to $\alpha 3$ mRNA actually derives from hybridization to other (nAChR?) RNA sequences.

\section{Results}

No specific labeling for any of the mRNAs studied was detected in E10 embryos by in situ hybridization. Starting with E11, labeling for all nAChR subunit mRNAs studied was noticed in several central and peripheral nervous structures of the embryos (Tables 2-6, Figs. 3-24).

\section{Central nervous system}

Overall patterns for each individual subunit. $\alpha 3$ subunit mRNA exhibits early and transient expression in both brain and spinal 

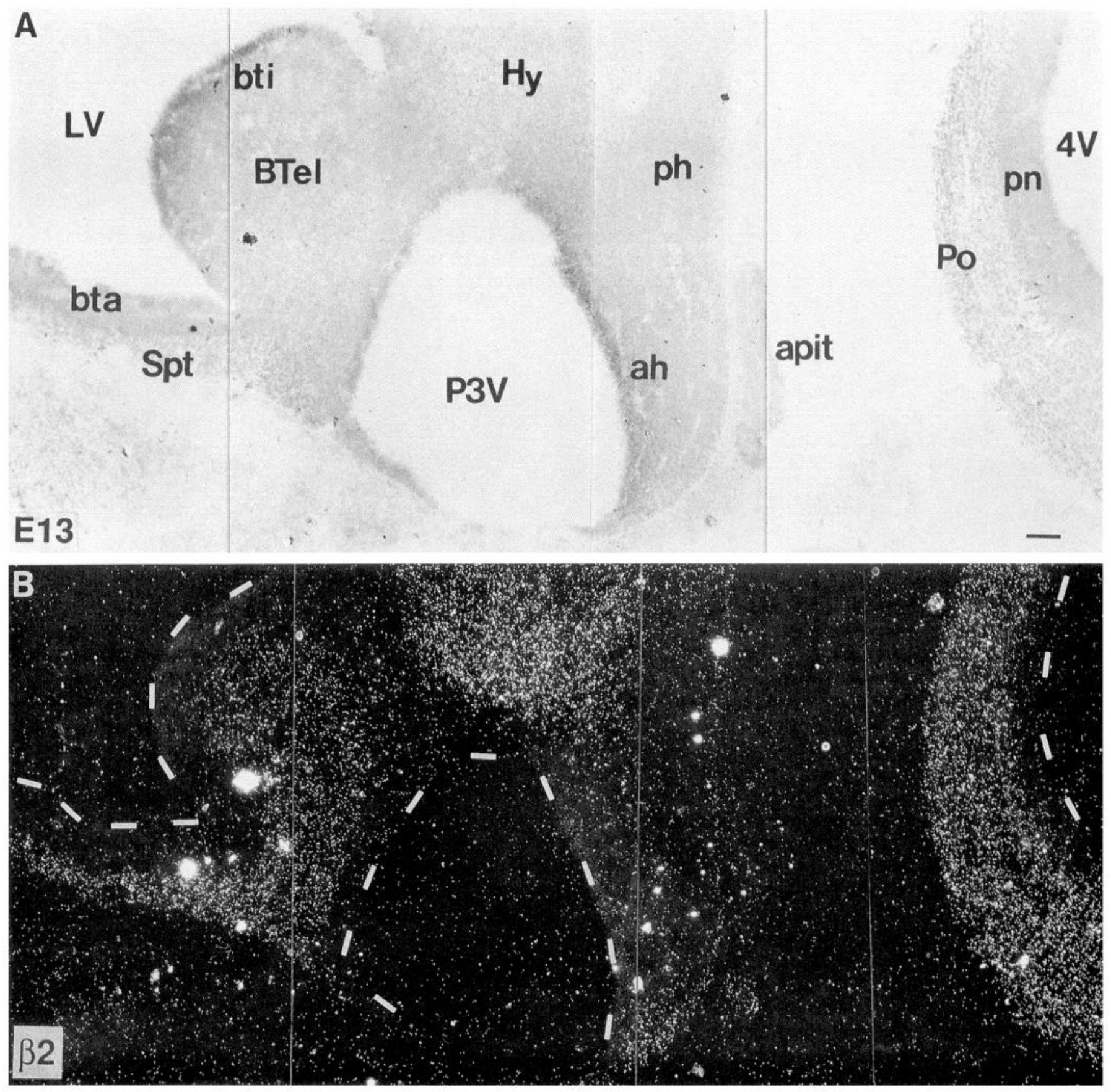

Figure 8. Dark-field microphotograph $(B)$ of emulsion autoradiograms showing $\beta 2 \mathrm{nAChR}$ subunit mRNA in sagittal sections of the basal telencephalon, diencephalon and pons of a E13 rat embryo. Dashed lines outline the borders of the ventricles. Abbreviations: ah, anterior hypothalamic neuroepithelium; apit, anterior pituitary; bta, basal telencephalic neuroepithelium, anterior part; BTel, basal telencephalic nuclei; bti, basal telencephalic neuroepithelium, intermediate part; $H y$, hypothalamic nuclei; $L V$, lateral ventricle; $P 3 V$, preoptic recess of the third ventricle; $p h$, posterior hypothalamic neuroepithelium; pn, pontine neuroepithelium; Po, pontine nuclei; Spt, septal nuclei; $4 V$, fourth ventricle. Scale bar, $100 \mu \mathrm{m}$.

cord. It is first detected at E11 in caudal CNS regions and, subsequently, in rostral CNS, reaching moderate to high levels at E12-13. Transcript levels markedly decrease at E15-17 to become undetectable at later ages in nearly all CNS areas. Yet, $\alpha 3$ subunit mRNA persists at a high level in the medial habenula up to perinatal (and adult) ages; in addition, low to moderate labeling is present at perinatal ages in the cerebellar primordium and in the ventral cochlear nucleus.

Initial expression of $\alpha 4$ subunit mRNA proceeds from caudal to rostral regions of the CNS. It first appears in the spinal cord and rhombencephalon (E11), then in the mesencephalon (E1112), ventral diencephalon and basal telencephalon (E12-13), dorsal diencephalon (E15) and finally in the cerebral cortex (E17-19). In subsequent prenatal and perinatal development, $\alpha 4$ mRNA is heterogeneously, but rather stably, expressed in many CNS nuclei.

$\beta 2$ subunit mRNA exhibits early, widespread and stable expression in the CNS. Starting from E11-12 it appears in nearly 

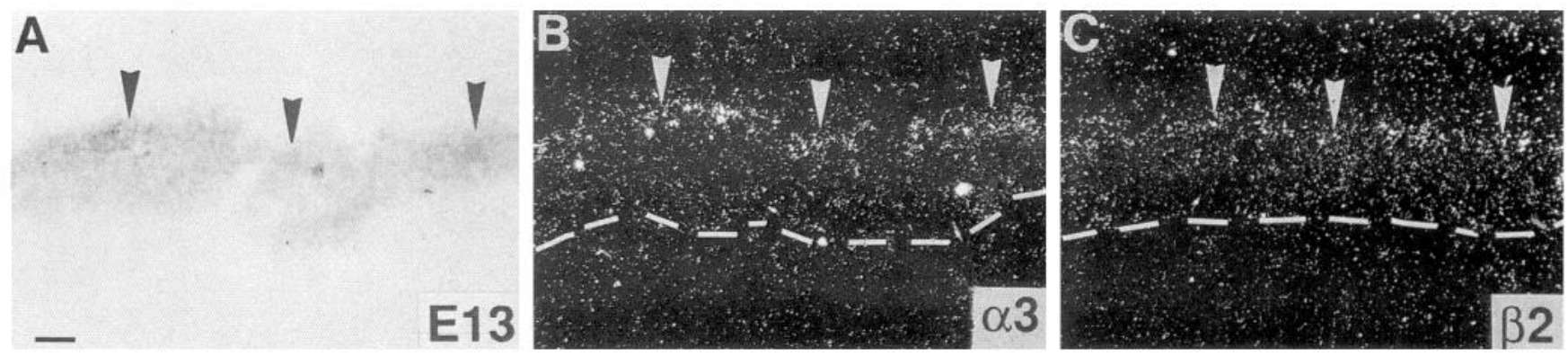

Figure 9. Dark-field microphotographs of emulsion autoradiograms showing $\alpha 3(B)$ and $\beta 2(C)$ nAChR subunit mRNAs in sagittal sections of the cerebral cortex of a E13 rat embryo. Arrows point to the external side (preplate) of the developing cerebral cortex. Dashed lines outline the internal border of the cerebral cortex. Scale bar, $100 \mu \mathrm{m}$.

all CNS regions where postmitotic cells are present and in a relatively homogeneous manner. The intensity of labeling is highest between E13 and E15 and thereafter slightly declines.

$\beta 4$ subunit mRNA is initially expressed in the spinal cord and caudal parts of the brain similarly to the other subunits. However, this expression is transient; $\beta 4$ transcript becomes undetectable after E13 in spinal cord and brain, with the exception of medial habenula, pineal gland, and a few other areas (corresponding to those expressing low to moderate levels of $\alpha 3$ transcript, see above).

Brain. At E11, we detected all four nAChR subunit mRNAs in the rhombencephalon and $\alpha 3, \alpha 4$, and $\beta 2$ mRNAs in the mesencephalon (see Table 2, Fig. 3). Patches of specific labeling for all subunit mRNAs were observed on the external side of the neural tube. Yet, $\alpha 3, \alpha 4$, and $\beta 2$ transcripts were present both ventrally and dorsally, whereas $\beta 4$ labeling was restricted to the ventral part of the brainstem. No specific labeling was detected at diencephalic and telencephalic levels.

From E12 to E13, $\alpha 3, \alpha 4$, and $\beta 2$ mRNA levels strikingly increased in the brain. On the other hand, $\beta 4$ mRNA levels peaked at E12 and were already reduced at E13 (Table 2, Figs. 4-9). In addition, the distribution of $\beta 4$ mRNA appeared more restricted than that of the other transcripts. Overall, $\beta 2$ mRNA was detected in most brain areas where differentiated cells were present (Fig. 8).

For instance, at E12, and more clearly at E13, $\beta 2$ was detected in the ventral diencephalon, where many postmitotic cells are present, but not in the dorsal diencephalon where postmitotic
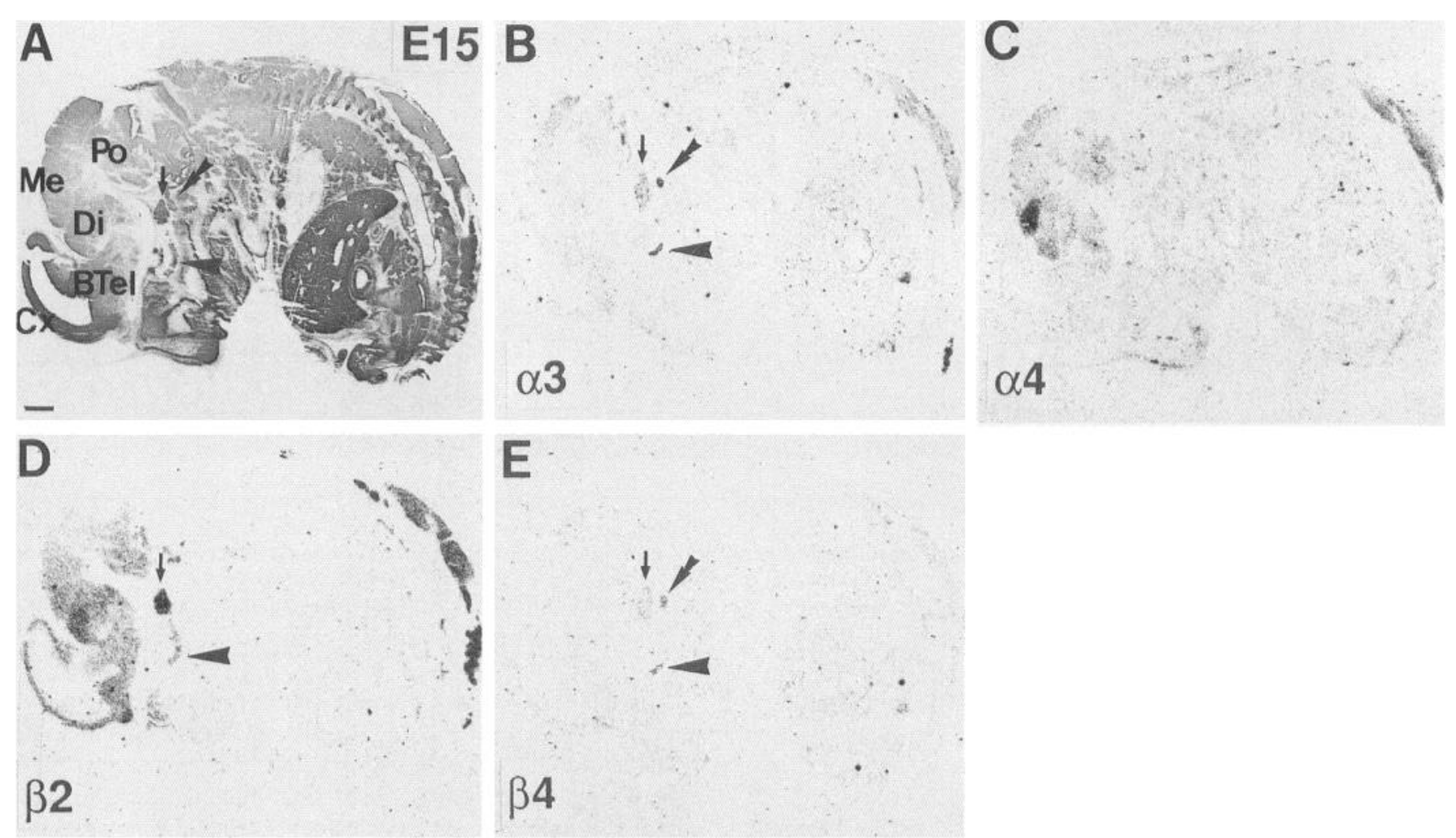

Figure 10. Bright-field microphotographs of film autoradiograms showing nAChR subunit mRNAs in sagittal sections of a E15 rat embryo. The nAChR subunit mRNA labeled is indicated in each panel. A shows toluidine blue staining. Arrows, arrowheads, and double arrowheads point to the trigeminal ganglion, the sphenopalatine ganglion and the otic ganglion, respectively. Abbreviations: $B T e l$, basal telencephalon; $C x$, cerebral cortex; $D i$, diencephalon; $M e$, mesencephalon; Po, pons. Scale bar, $1 \mathrm{~mm}$. 


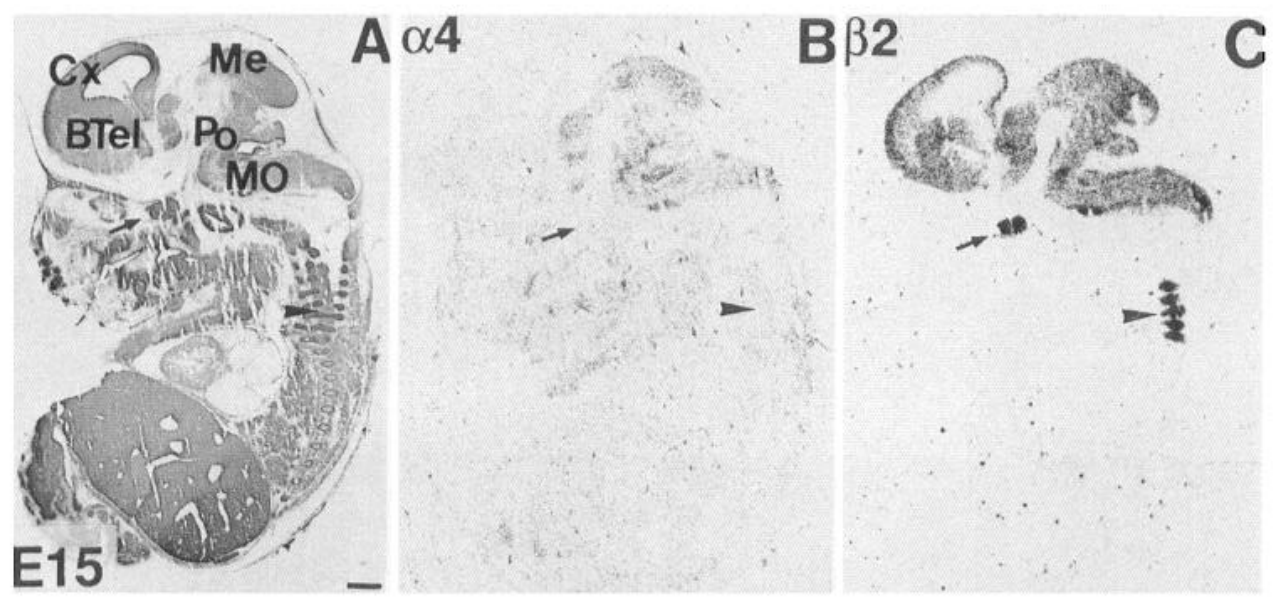

Figure 11. Bright-field microphotographs of film autoradiograms showing nAChR subunit mRNAs in sagittal sections of a E15 rat embryo. The nAChR subunit mRNA labeled is indicated in each panel. $A$ shows toluidine blue staining. As no labeling for $\alpha 3$ and $\beta 4$ mRNAs was visible at this anatomical level, the respective panels have been omitted. Arrows point to the trigeminal ganglion and arrowheads to the dorsal root ganglia. Abbreviations: $\mathrm{BTel}$, Basal telencephalon; $C x$, cerebral cortex; $\mathrm{Me}$, mesencephalon; $M O$, medulla oblongata; $P o$, pons. Scale bar, $1 \mathrm{~mm}$.

cells are rare (Altman and Bayer, 1978, 1979a,b). $\alpha 3$ and $\alpha 4$ mRNAs showed a more discrete distribution, which partially overlapped that of $\beta 2$ mRNA.

In the rhombencephalon labeling for $\mathrm{nAChR}$ subunits was mainly in the ventral and in the dorsocaudal parts, whereas the roof of the IV ventricle was devoid of labeling for any mRNA. Throughout the brainstem, the labeling had a rather patchy appearance. When a positive patch was identified in several consecutive sections, the labeling for the different mRNAs was found to coincide (see, e.g., Fig. 6). This suggests that developing clusters of cells may coexpress several nAChR subunit mRNAs.

In the ventral diencephalon different intensities of labeling (weak for $\beta 4$, moderate for $\alpha 3$ and $\alpha 4$, and intense for $\beta 2$ ) for all transcripts were noticed at E12 and more clearly at E13. At E13, low to intermediate labeling for $\alpha 3$ and $\beta 2$, but not $\alpha 4$, was observed in the external part of the embryonic cerebral cortex, probably corresponding to the first cortical postmitotic neurons (preplate) (Fig. 9), and in the hippocampal formation. Specific labeling for $\alpha 3, \alpha 4$, and $\beta 2$ mRNAs was also present in already differentiated basal telencephalic areas (Fig. 8).

At E15, the general pattern of labeling of $\alpha 4$ and $\beta 2$ mRNAs diverged from that of $\alpha 3$ and $\beta 4$ (Table 2, Figs. 10-13). $\alpha 4$ and $\beta 2$ subunit mRNAs continued to be detected in a diffuse pattern whereas labeling for $\alpha 3$ mRNA markedly declined, and that for $\beta 4$ disappeared from the vast majority of brain areas labeled at earlier developmental days. Moderate to high $\alpha 3$ and $\beta 4$ mRNA levels were restricted to the medial habenula. Although exhib- iting relatively similar patterns of regional distribution, $\alpha 4$ and $\beta 2$ mRNA labeling displayed some distinctive features. $\beta 2$ labeling was very high and homogeneous throughout the brain whereas $\alpha 4$ labeling appeared more discrete. In addition, $\beta 2$ was clearly expressed in the cortical plate and less intensely in the other histogenetic layers of the cerebral cortex, whereas $\alpha 4$ was not detected in these regions (Fig. 12).

At embryonic ages E17 and E19 and in the first postnatal day, the distribution patterns delineated at E15 were substantially maintained (Table 2, Figs. 14-17). $\beta 2$ remained diffusely distributed throughout the brain. $\alpha 4$ displayed a relatively more heterogeneous distribution, being absent in the basal ganglia and olfactory bulb and highly concentrated in the ventromedial hypothalamic nucleus, several thalamic nuclei and a few brainstem nuclei (Table 2), $\alpha 3$ and $\beta 4$ were highly expressed in the medial habenula (Figs. 14, 16). In addition, the ventral cochlear nucleus and some portions of the external germinal layer and neuroepithelium of the cerebellum contained low to moderate $\alpha 3$ and $\beta 4$ transcript levels.

In the cerebral cortex, high levels of $\beta 2$ mRNA were present in the cortical plate at E17 (Figs. 14, 15), whereas the transient histogenetic cell layers below the cortical plate displayed lower levels of the transcript. This pattern of labeling persisted in the following days. $\alpha 4$ first became detectable in the cortical plate at E19 (Fig. 17). Weak to moderate labeling was, however, observed in the subplate starting from E17. No specific labeling for $\alpha 3$ and $\beta 4$ was noticed in any layer of the developing cerebral cortex in the late prenatal period.
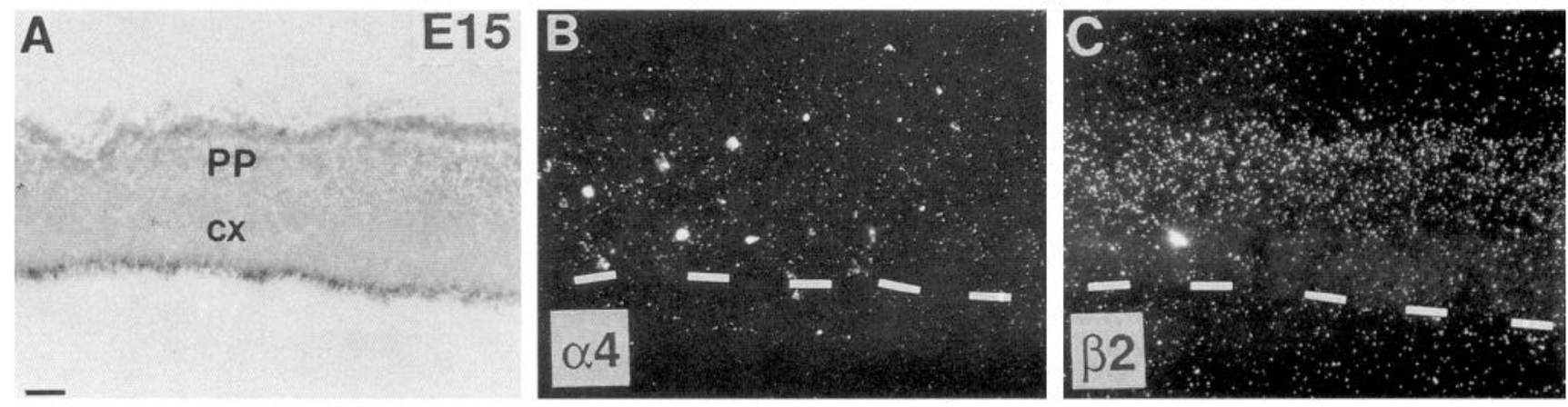

Figure 12. Dark-field microphotographs of emulsion autoradiograms showing $\alpha 4(B)$ and $\beta 2(C)$ nAChR subunit mRNAs in sagittal sections of the cerebral cortex of a E15 rat embryo. Dashed lines outline the internal border of the cerebral cortex. Abbreviations: $c x$, cortical neuroepithelium; $P P$, cortical preplate. Scale bar, $100 \mu \mathrm{m}$. 

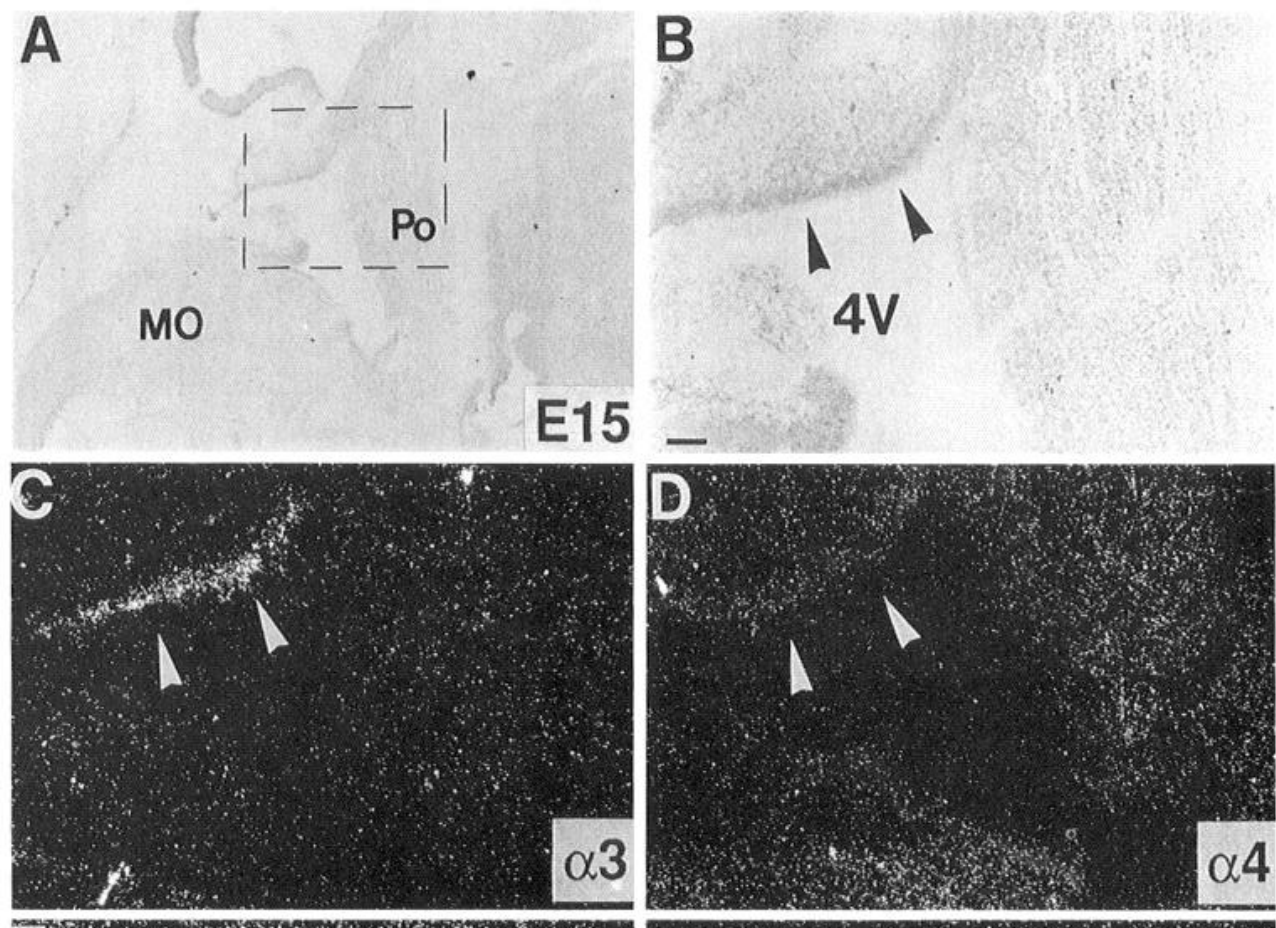

Figure 13. Dark-field microphotographs of emulsion autoradiograms showing $\mathrm{nAChR}$ subunit mRNAs in sagittal sections of the roof of the IV ventricle $(4 \mathrm{~V})$ of a E15 rat embryo. The nAChR subunit mRNA labeled is indicated in each panel. $A$ and $B$ show toluidine blue staining. In $A$ the rectangular frame delineates the area which is magnified in the other panels. The arrowheads point to the neuroepithelium of the cerebellar primordium. Abbreviations: $M O$, medulla oblongata; $P o$, pons. Scale bar, $100 \mu \mathrm{m}$.
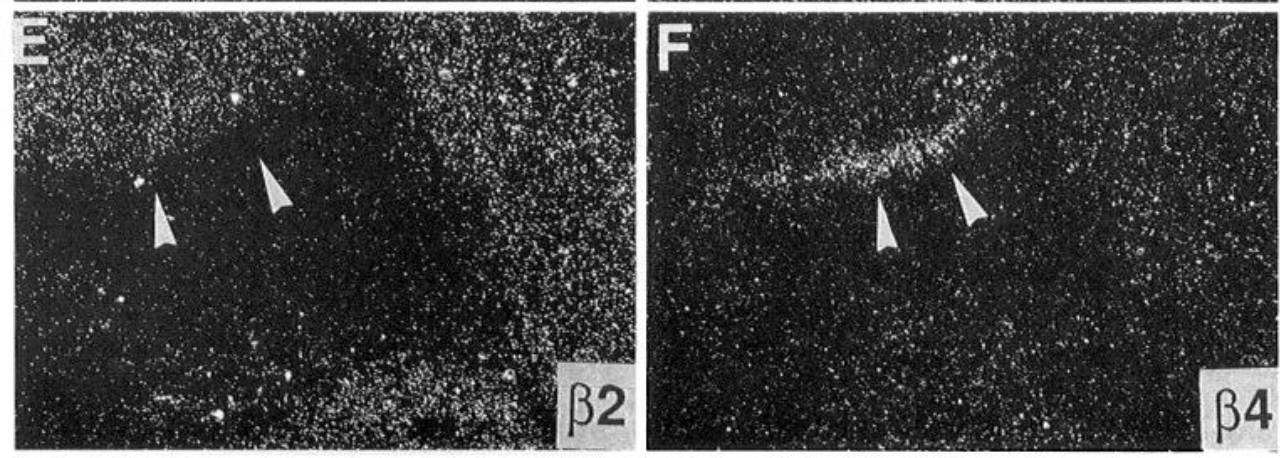

Spinal cord. Overall, appearance of $\mathrm{nAChR}$ subunit transcripts in the spinal cord was extremely precocious and transient (Table 3). From E11 to E13 (Figs. 3, 5), moderate to very high levels of $\alpha 3, \alpha 4, \beta 2$, and $\beta 4$ mRNAs were present in the spinal cord. At E11, specific labeling for all subunit mRNAs was observed in the ventrolateral part of the spinal cord (Fig. 3), where the first differentiated neurons occur (Kaufman, 1992). A thin layer of cells positive for $\alpha 3, \alpha 4$, and $\beta 2$ was also detected on the lateral side of the dorsal spinal cord. At later embryonic stages (E15-E17), labeling for $\alpha 3$ and $\alpha 4$ markedly and slightly decreased, respectively, whereas $\beta 2$ mRNA labeling remained high and $\beta 4$ mRNA became undetectable (see Figs. 10, 14). At P4, no labeling for $\alpha 3$ and $\beta 4$ mRNAs was present in the spinal cord, whereas $\alpha 4$ and $\beta 2$ were still weakly and diffusely expressed in both ventral and dorsal horns.

Pineal gland. In this structure of epithalamic origin, $\beta 4$ was the only subunit mRNA detected at prenatal ages (from E17) (Table 2, Fig. 14). At P0 and P4, $\alpha 3$ and $\beta 2$ subunit mRNAs were also observed, at high and low levels, respectively. The two epithalamic derivatives, the habenula and the pineal gland, are the only brain structures which express high levels of $\alpha 3$ and $\beta 4$ mRNAs in the perinatal period. This pattern resembles that of autonomic motor and sensory ganglia (see below). Interestingly, both neurons of the medial habenula and pinealocytes of the pineal gland are morphologically (Gottesfeld, 1983; Bow- ers et al., 1984) and functionally (at least the pineal gland, Reiter, 1989) linked to the sympathetic system.

\section{Retina}

Labeling for all $\mathrm{nAChR}$ subunit mRNAs studied was present in the optic stalk in E12-13 embryos (Table 4). At E13, moderate to high labeling for $\alpha 3$ and $\beta 4$ mRNAs was present in the retina, whereas $\alpha 4$ and $\beta 2$ mRNAs were not detected. Starting from E15 high labeling for the four mRNAs was concentrated on the vitreal side of the retinal epithelium (Fig. 19). From this age up to P4, in agreement with Hoover and Goldman (1992) data, the four $\mathrm{nAChR}$ subunit mRNAs were expressed in the neural retina, though at progressively lower levels. Starting from E15 and up to P0, specific labeling for $\alpha 4 \mathrm{mRNA}$ of moderate and then weak intensity was detected in the optic nerve (Fig. 20). Specific grains appeared concentrated over cell bodies (Fig. 21) likely representing glial cells (Colello and Guillery, 1992).

\section{Dorsal root ganglia}

At E11, the first ganglia appearing at the mid-trunk level, showed high labeling for $\alpha 3$, and moderate labeling for $\alpha 4, \beta 2$ and $\beta 4 \mathrm{nAChR}$ subunit mRNAs (Table 5, Figs. 4, 10, 11, 15). At E12 and E13 high labeling for $\alpha 3, \alpha 4$, and $\beta 2$ and moderate for $\beta 4 \mathrm{nAChR}$ subunit mRNAs was detected (Fig. 4). After this stage and up to P4, $\alpha 3$ labeling decreased to moderate levels, 
A

$\alpha 3$

C

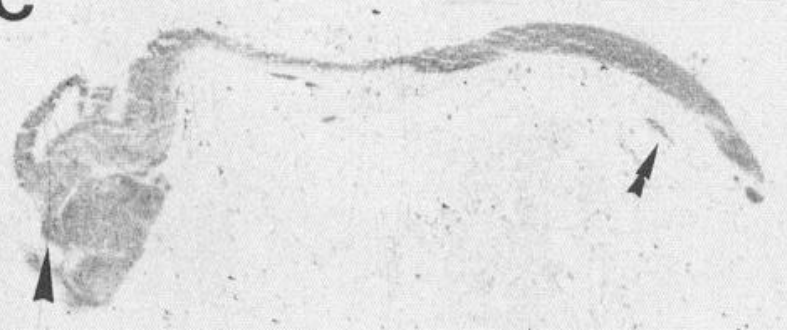

$\beta 2$

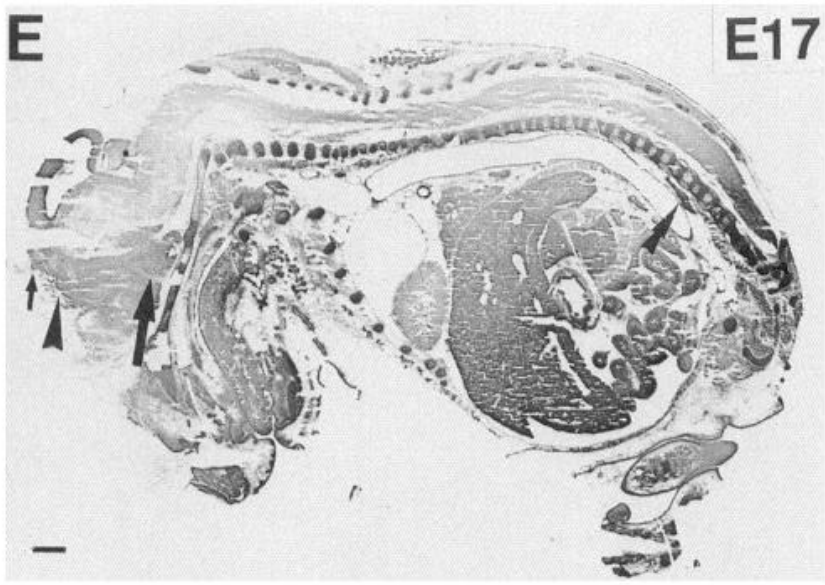

B

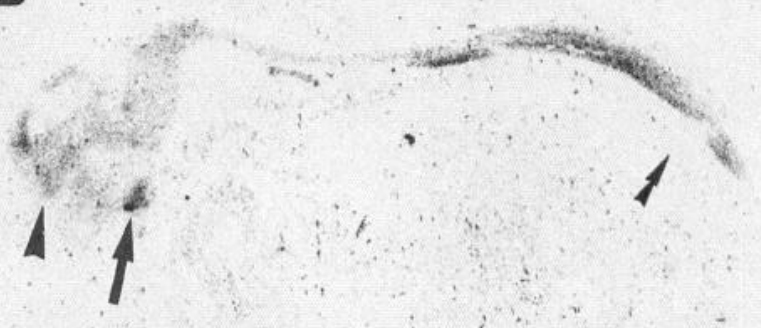

$\alpha 4$

D

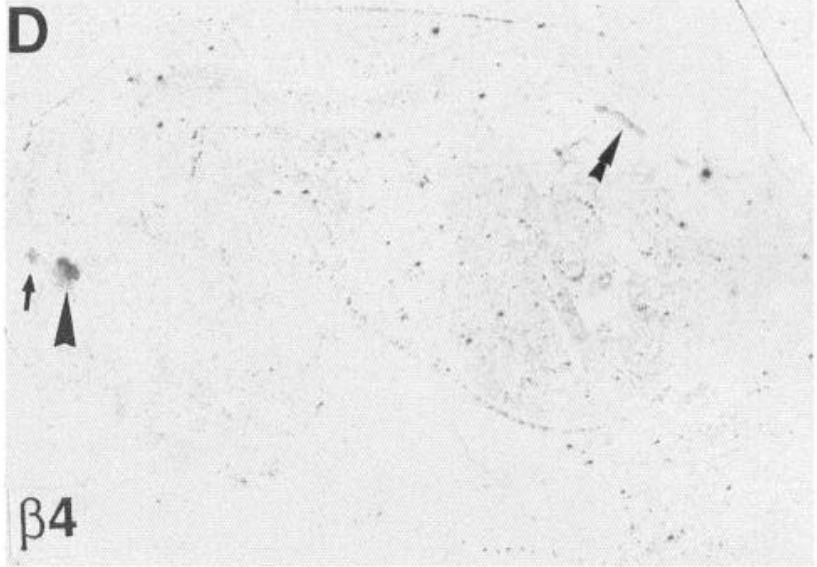

Figure 14. Bright-field microphotographs of film autoradiograms showing nAChR subunit mRNAs in sagittal sections of a E17 rat embryo. The nAChR subunit mRNA labeled is indicated in each panel. E shows toluidine blue staining. Big and small arrows, arrowheads, and double arrowheads point to the ventromedial hypothalamic nucleus, the epiphysis, the medial habenula, and lumbar sympathetic ganglia, respectively. Scale bar, $1 \mathrm{~mm}$.

whereas $\beta 2$ labeling remained stably elevated. On the other hand, $\alpha 4$ and $\beta 4$ subunit mRNAs became undetectable starting from E15 and E17, respectively.

\section{Cranial nerve and sympathetic ganglia}

We observed a wide spectrum of transcript distribution in cranial nerve and sympathetic ganglia (Table 6). As in other neural structures, expression of nAChR subunit mRNAs was precocious and, in some cases, transient.

$V$ nerve. The trigeminal ganglion, a somatic sensory structure, also containing some visceral sensory neurons projecting to the buccal mucosa, is associated with the $\mathrm{V}$ nerve. It exhibited specific labeling for all $\mathrm{nAChR}$ mRNAs studied starting from E11 (Fig. 3). $\alpha 4$ and $\beta 4 \mathrm{mRNAs}$ were transiently detected peaking at E12-13 and decreasing thereafter to become undetectable at E15-17 (Figs. 10, 11, 16, 22). $\beta 2$ mRNA labeling reached high intensity at E13 and remained elevated at all subsequent embryonic and postnatal ages investigated (Figs. 10, 11, 16, 22). $\alpha 3$ mRNA exhibited two peaks of expression. High levels were detected at E12-13 followed by a marked decrease to very low 

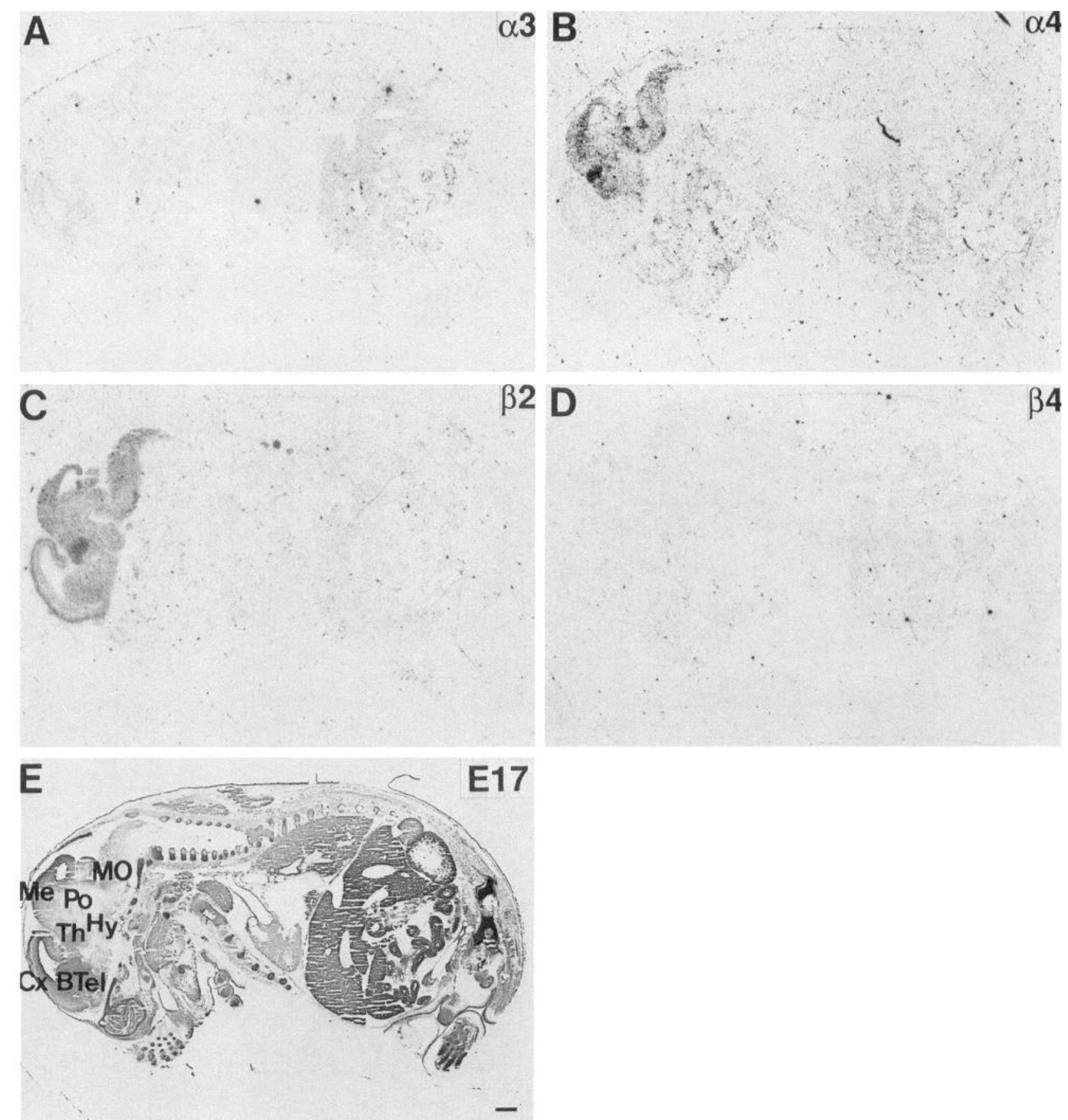

Figure 15. Bright-field microphotographs of film autoradiograms showing nAChR subunit mRNAs in sagittal sections of a E17 rat embryo. The nAChR subunit mRNA labeled is indicated in each panel. $E$ shows toluidine blue staining. Abbreviations: $B T e l$, basal telencephalon; $C x$, cerebral cortex; $\mathrm{Hy}$, hypothalamus; $\mathrm{Me}$, mesencephalon; $M O$, medulla oblongata; $\mathrm{Po}$, pons; $\mathrm{Th}$, thalamus. Scale bar, $1 \mathrm{~mm}$.

levels in the following prenatal days (Figs. 10, 16, 22) and first postnatal day. At P4, low to moderate levels of $\alpha 3$ mRNA were again visible in the trigeminal ganglion.

VII nerve. Two ganglia associated with the VII nerve, that is, the geniculate ganglion (gustatory sensory) and the sphenopalatine ganglion (parasympathetic motor) were investigated. At E11-12 the anlage of the VII ganglion could not be distinguished from that of the VIII ganglia. At these ages all four nAChR subunit mRNAs were expressed in the VII/VIII complex. Starting from E13, when a distinct geniculate ganglion segregated, only the $\beta 2$ mRNA was detectable (Fig. 22). The sphenopalatine ganglion was clearly recognizable starting from E15. At this age, high labeling for $\alpha 3, \beta 2$, and $\beta 4$ was found. At all subsequent prenatal and postnatal ages up to P4 (Figs. 10, 23) high levels of $\alpha 3$ and $\beta 4$ mRNAs (as well as somewhat lower levels for $\beta 2$ ) were observed.

VIII nerve. The ganglia associated with the VIII cranial nerve, that is, the cochlear and vestibular ganglia, expressed moderate to high levels of $\alpha 4$ and $\beta 2$ subunit mRNAs from E13 through P0 (Fig. 22). At E11-12 the aggregate of cells corresponding to 

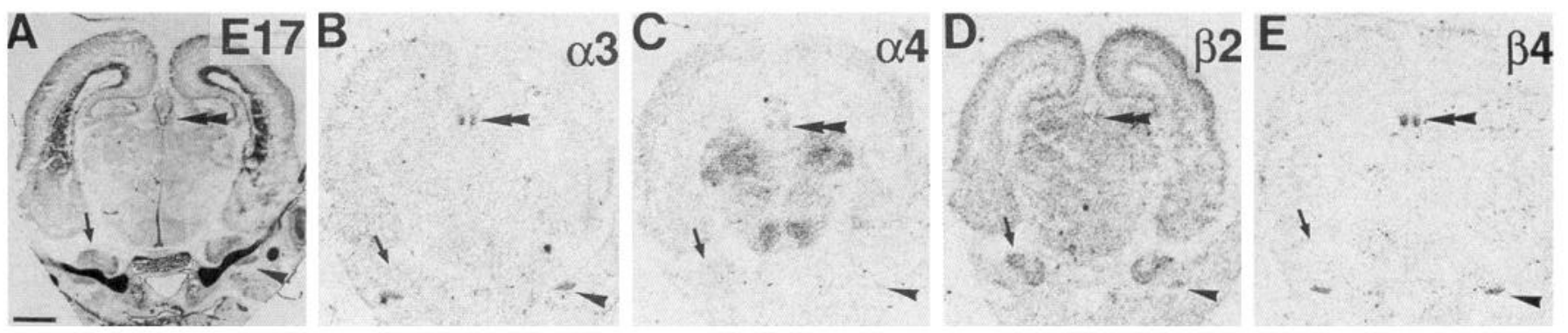

Figure 16. Bright-field microphotographs of film autoradiograms showing $\mathrm{nAChR}$ subunit mRNAs in coronal sections at midthalamic level of a E17 rat embryo. The nAChR subunit mRNA labeled is indicated in each panel. A shows toluidine blue staining. Arrows point to the trigeminal ganglion, arrowheads, to the otic ganglion and double arrowheads to the medial habenula. Scale bar, $1 \mathrm{~mm}$.

the VII and VIII ganglia was positive for all the $\mathrm{nAChR}$ subunit mRNAs studied.

$I X$ and $X$ nerves. In adult animals, three ganglia are associated with the IX cranial nerve, that is, the superior (somatic sensory), inferior (visceral sensory), and otic (parasympathetic motor) ganglia. A ganglion is associated with the $\mathrm{X}$ nerve, the inferior or nodose (visceral sensory) ganglion. At E11, it was not possible to distinguish the various ganglia associated with the IX and $\mathrm{X}$ nerves. At this age low $(\beta 2)$ to high $(\alpha 3)$ levels of labeling for the four $n A C h R$ subunit mRNAs were present in the primordia of these ganglia. At later ages a different pattern of labeling was observed in the superior (somatic sensory) and two inferior (visceral sensory) ganglia. In IX superior ganglion, the initial appearance of all $\mathrm{nAChR}$ subunit mRNAs was followed by the exclusive expression of $\beta 2$ mRNA (starting from E17) (Fig. 24). On the other hand, with the exception of $\alpha 4$ mRNA labeling which disappeared at E15, the other mRNAs persisted at moderate to high levels up to $\mathrm{P} 4$ in the inferior (visceral sensory) IX and X ganglia (Fig. 24). The otic ganglion could clearly be identified starting from E15. High labeling for $\alpha 3$ and $\beta 4$ mRNAs, and moderate to low for $\beta 2$ mRNA, were present at all ages studied (Figs. 16, 22).

Sympathetic system. In every instance in which either cervical or thoracolumbar sympathetic ganglia were identified, at any age, the same pattern of labeling, viz strong labeling for $\alpha 3$ mRNA and moderate to strong labeling for $\beta 2$ and $\beta 4$ mRNAs (Figs. 14, 24), was observed.

Overall, during prenatal and perinatal development the patterns of nAChR subunit expression seem specific for the different categories of ganglia (Table 7). In the somatic and gustatory sensory ganglia (trigeminal, geniculate, and superior glossopharyngeal ganglia) the initial expression of all $n A C h R$ subunits studied is followed by a restriction to only the $\beta 2$ transcript. Some expression of $\alpha 3$ mRNA is still detectable in the trigeminal ganglion which also contains some visceral sensory neurons projecting to the buccal mucosa. Interestingly, the same pattern of expression was detected in the dorsal root ganglia (see above) which also contain some visceral sensory neurons. Autonomic
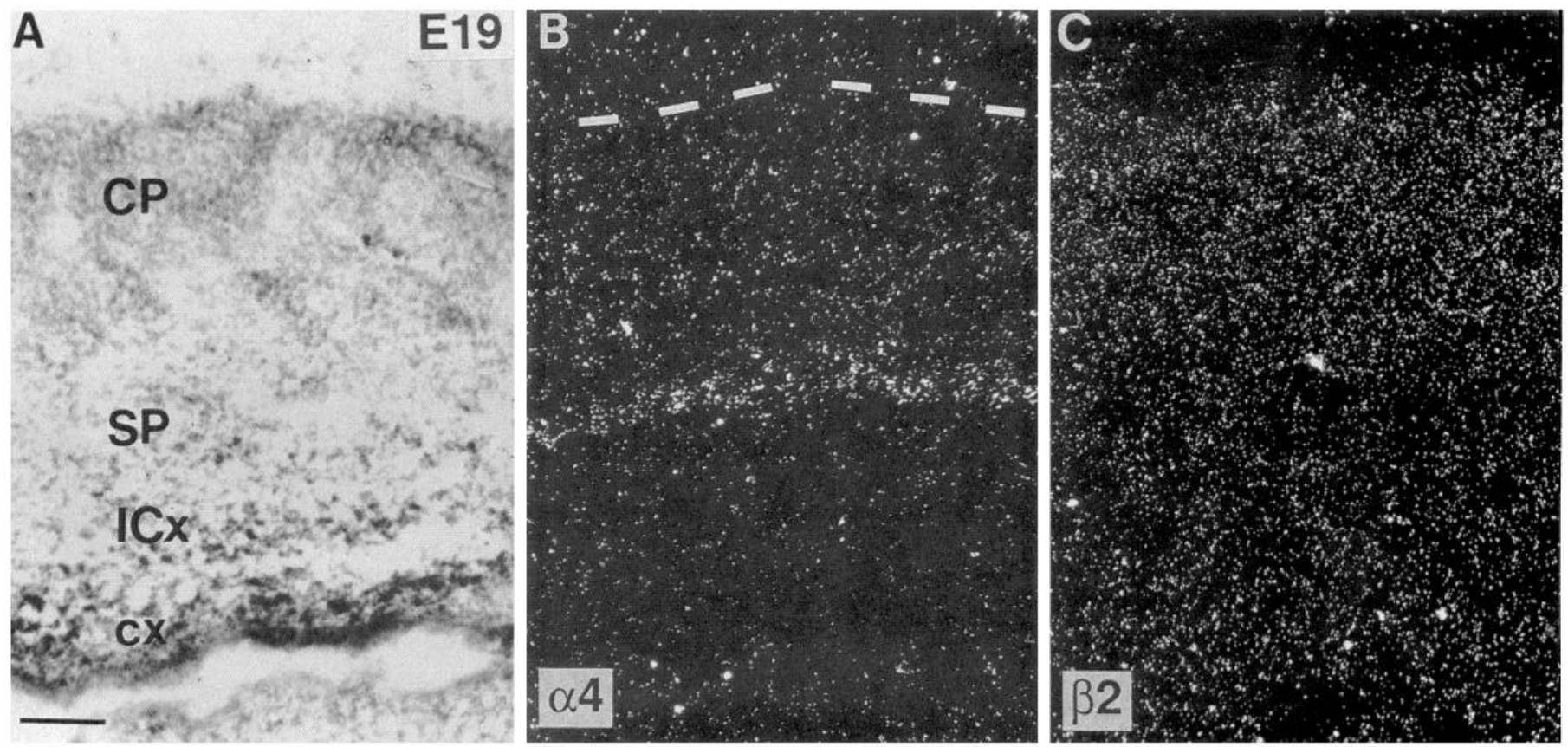

Figure 17. Dark-field microphotographs of emulsion autoradiograms showing $\alpha 4(B)$ and $\beta 2(C)$ nAChR subunit mRNAs in coronal sections of the cerebral cortex of a E19 rat embryo. Dashed lines outline the external border of the cerebral cortex. Abbreviations: $C P$, cortical plate; $c x$, cortical neuroepithelium; $I C x$, intermediate cortical layer; $S P$, cortical subplate. Scale bar, $100 \mu \mathrm{m}$. 


\begin{tabular}{llllll}
\hline $\begin{array}{l}\text { Table 3. } \\
\text { cord }\end{array}$ & \multicolumn{6}{c}{ Development of nAChR subunit mRNAs in the spinal } \\
& & & & & \\
& & & & & \\
E11 & vent & +++ & +++ & ++ & ++ \\
& dors & + & ++ & + & - \\
E12 & vent & +++ & +++ & +++ & ++ \\
& dors & + & +++ & + & + \\
E13 & vent & +++ & +++ & +++ & ++ \\
& dors & +++ & +++ & ++ & + \\
E15 & vent & ++ & ++ & +++ & + \\
& dors & + & + & +++ & - \\
E17 & vent & + & ++ & +++ & - \\
& dors & + & + & +++ & - \\
P4 & vent & - & + & + & - \\
& dors & - & + & + & - \\
& & & & + & +
\end{tabular}

Scores were attributed as follows: + , low level; ++ , intermediate level; +++ high level. Abbreviations: dors, dorsal; vent, ventral.

ganglia, both sensory and motor (sympathetic, sphenopalatine, otic, inferior glossopharyngeal, and vagal ganglia) express $\alpha 3$, $\beta 4$, and $\beta 2$ mRNAs. Finally, acoustic and vestibular ganglia only express $\alpha 4$ and $\beta 2$ mRNAs.

\section{Summing up of regional patterns of $n A C h R$ subunit $m R N A$ distribution during development}

Although each PNS structure and CNS region studied displayed particular developmental changes in the expression of $\mathrm{nAChR}$ subunit mRNAs (see Tables 2-6), three main developmental patterns were recognized:

Pattern A. All four subunit mRNAs are expressed early in development, but, subsequently, during prenatal development, the expression of some of these subunits is repressed.

Pattern B. $\alpha 3$ and $\beta 2$ subunit mRNAs are detected early in

Table 4. Development of nAChR subunit mRNAs in the retina and optic nerve
$\alpha 3$
$\alpha 4$
$\beta 2$ $\beta 4$

E12

Optic stalk

E13

Optic stalk

Retina

E15

Optic nerve

Retina

E17

Optic nerve

Retina

E19

Optic nerve

Retina

P0

Optic nerve

Retina

P4

Retina

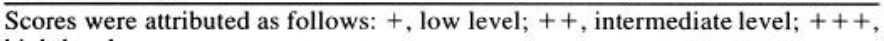
high level.
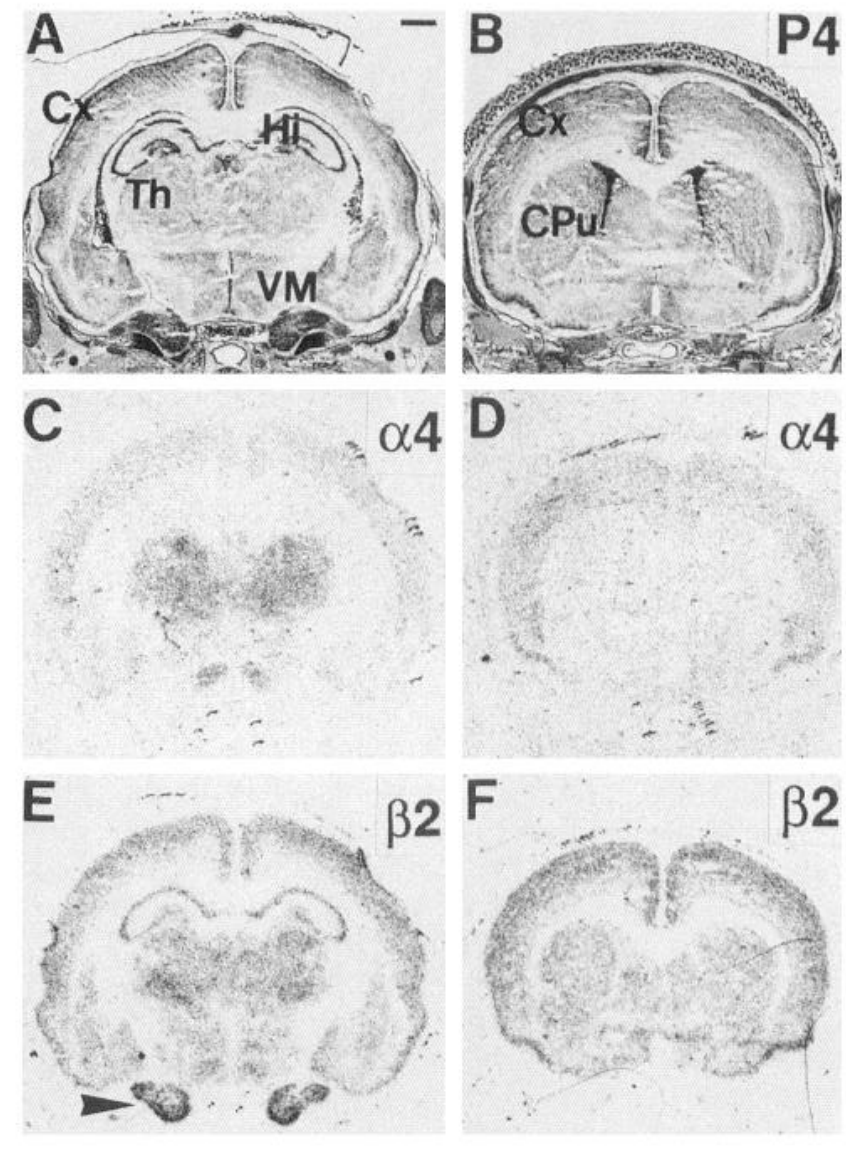

Figure 18. Bright-field microphotographs of film autoradiograms showing nAChR subunit mRNAs in coronal sections at midthalamic $(A$, $C, E)$ and striatal $(B, D, F)$ levels of a $\mathrm{P} 4$ rat. The nAChR subunit mRNA labeled is indicated in each panel. $A$ and $B$ show toluidine blue staining. Note the high $\beta 2$ mRNA labeling in the trigeminal ganglia (arrowhead in $E$ ). Abbreviations: $C P u$, caudate-putamen; $C x$, cerebral cortex; $H i$, hippocampus; $T h$, thalamus; $V M$, ventromedial hypothalamic nucleus. Scale bar, $1 \mathrm{~mm}$.

development, but, subsequently, during prenatal development, the $\alpha 3$ subunit disappears followed by the appearance of the $\alpha 4$ subunit.

Pattern $C$. The subunit mRNAs which are initially expressed remain stably expressed throughout prenatal and perinatal postnatal development.

Pattern A can be recognized in the majority of neural structures analyzed (caudal brain, spinal cord, dorsal root ganglia, trigeminal, geniculate, glossopharyngeal, and vagal ganglia). In these structures the expression of some nAChR subunit mRNAs ( $\alpha 3$ and $\beta 4$ in the brain and spinal cord, $\alpha 4$ and $\beta 4$ in the dorsal root ganglia, $\alpha 4$ in the visceral sensory ganglia, and $\alpha 3, \alpha 4$, and $\beta 4$ in the somatic sensory ganglia) was precocious and transient. For instance, in the brain the initial (E11-13) widespread expression of $\alpha 3$ (and to a lesser extent $\beta 4$ ) mRNA was followed by a repression to levels undetectable with the present technique. In the late prenatal period high levels of $\alpha 3$ and $\beta 4$ transcripts were found only in the medial habenula starting at E15 when differentiated cells form in the nucleus (Altman and Bayer, 1979a). In the rostral part of the brain, with the exception of cerebral cortex, only certain subunits $(\beta 2, \alpha 4$, and/or $\alpha 3)$ were detected at E12-13. However, similar to what happens in the caudal brain, $\alpha 3$ expression was transient. 

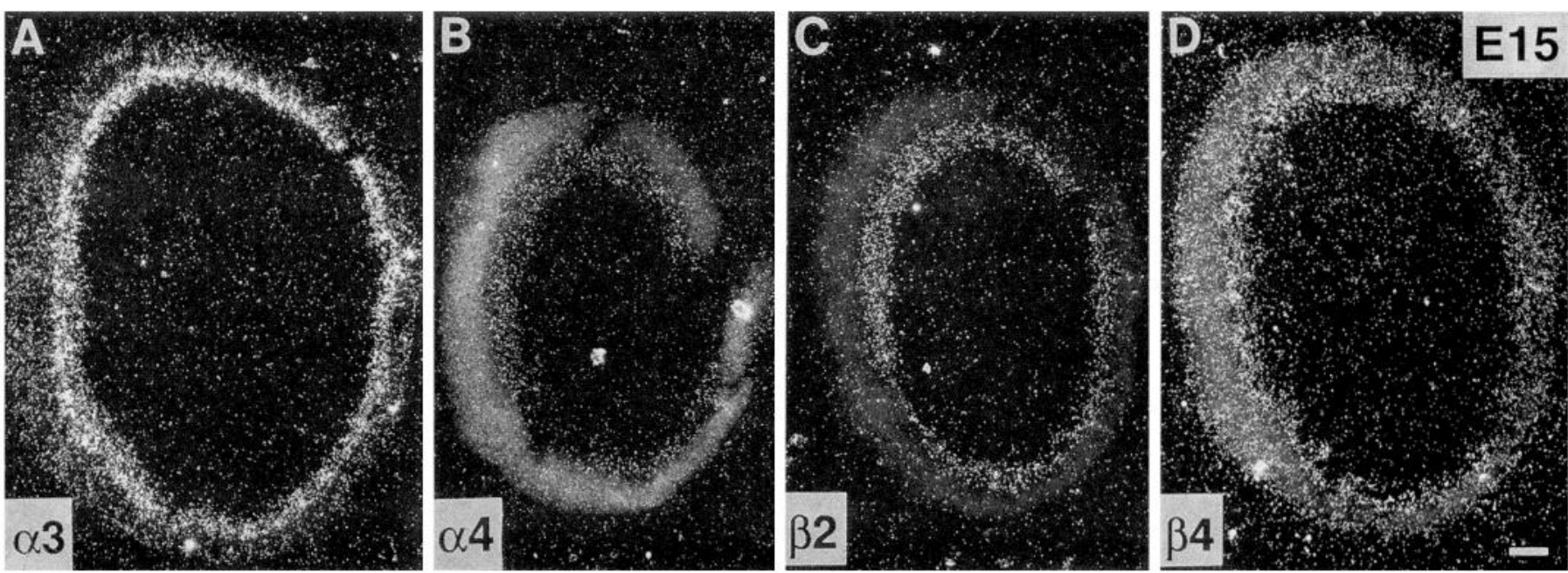

Figure 19. Dark-field microphotographs of emulsion autoradiograms showing nAChR subunit mRNAs in sagittal sections of the retina of an E15 rat embryo. The nAChR subunit mRNA labeled is indicated in each panel. The images are taken from sections cut from the same animal and processed in the same experiment, in which $\alpha 4$ and $\beta 2$ labeling was in absolute terms less strong than $\alpha 3$ and $\beta 4$ labeling. However, the intensity of $\alpha 4$ and $\beta 2$ labeling in the retina was high when compared to that of the other positive structures in the same experiment. Scale bar, $100 \mu \mathrm{m}$.

Pattern B is observed in the cerebral cortex. In this region $\mathrm{nAChR}$ mRNA development is peculiar in several respects. $\alpha 3$ and $\beta 2$ were first detected at E12-13 in the preplate. Subsequently, $\alpha 3$ mRNA disappeared and $\beta 2$ remained the only subunit expressed in the cortical plate (constituted by the neurons which will form the mature cerebral cortex) until E19 when $\alpha 4$ started to be detected throughout the plate. $\beta 2$ was also expressed in the histogenetic layers of the cortex (subplate, intermediate and subventricular zones) initially alone and then (E17) together with $\alpha 4$ (subplate). As in the other structures analyzed, $\beta 2$ was highly expressed in cerebral cortex around the time of neuronal differentiation. However, at variance with other CNS areas, $\alpha 4$ mRNA appearance was not temporally related to the time of the last mitosis of cortical neurons. The final mitosis of the neurons that will form the cortical plate takes place from E12 to E20 and follows an inside-out gradient (Angevine and Sidman, 1961). However, $\alpha 4$ started to be detected at the end of this period with no evident layer-related gradient. Interestingly, $\alpha 4$ mRNA appearance seems temporally correlated to the arrival of basal telencephalic afferents which penetrate into the cortical plate in the perinatal period, but are already present in the subplate at E17 (Koh and Loy, 1989; Semba, 1992). This evidence suggests that, similarly to $\alpha 2$ and $\beta 2$ in chick brain
(Daubas et al., 1990, Matter et al., 1990), innervation may directly stimulate $\alpha 4$ subunit gene expression in developing cortical neurons.

Pattern C is present in the retina, in the vestibulo-cochlear ganglia and in both the sympathetic and parasympathetic motor ganglia. In these last ganglia, the subunit transcripts initially detected $(\alpha 3, \beta 2$, and $\beta 4)$ persisted at a high level throughout prenatal and perinatal development. Accordingly, in both chicken parasympathetic and sympathetic ganglia, the same set of ACh-gated channels are recognized during prenatal development (Margiotta and Gurantz, 1989; Moss et al., 1989). In addition, no evidence for a switch in subunit composition (at least not in chick ciliary ganglion; Corriveau and Berg, 1993) has been presented to date.

At variance with our data in the rat, in chicken parasympathetic and sympathetic ganglia a marked (5-15-fold) increase in nAChR subunit mRNA levels, ACh binding, and response to ACh takes place during prenatal development, and temporally matches the arrival of cholinergic innervation and the formation of mature synapses (Margiotta and Gurantz, 1989; Moss et al., 1989; Corriveau and Berg, 1993). This discrepancy may reflect species differences. In fact, synaptogenesis as well as functional
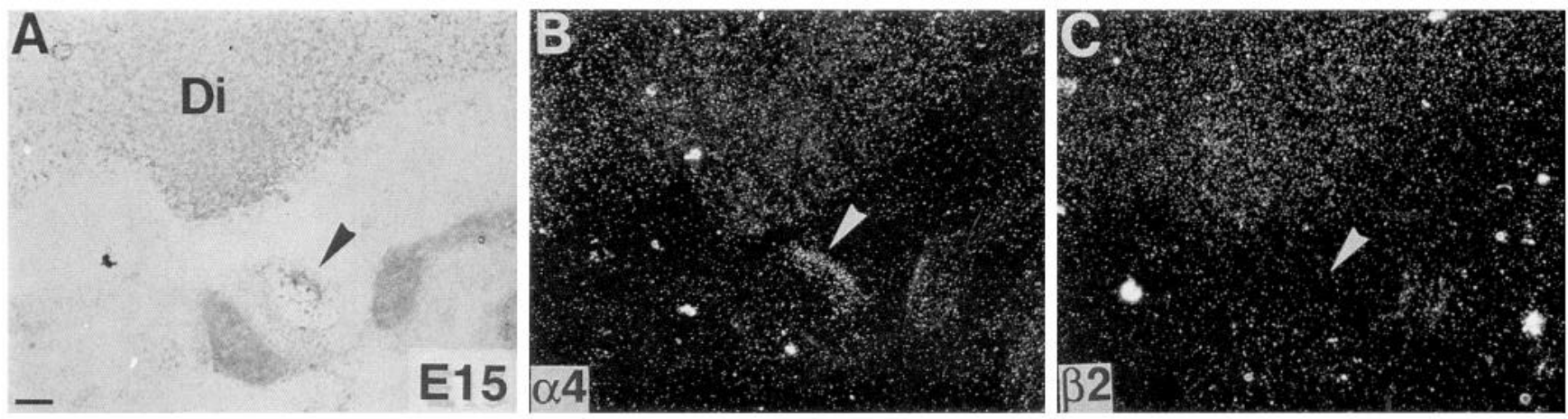

Figure 20. Dark-field microphotographs of emulsion autoradiograms showing $\alpha 4(B)$ and $\beta 2(C)$ nAChR subunit mRNAs in sagittal sections of the optic nerve of a E15 rat embryo. A shows toluidine blue staining. The arrowheads point to the optic nerve. Abbreviation: Di, diencephalon. Scale bar, $100 \mu \mathrm{m}$ 

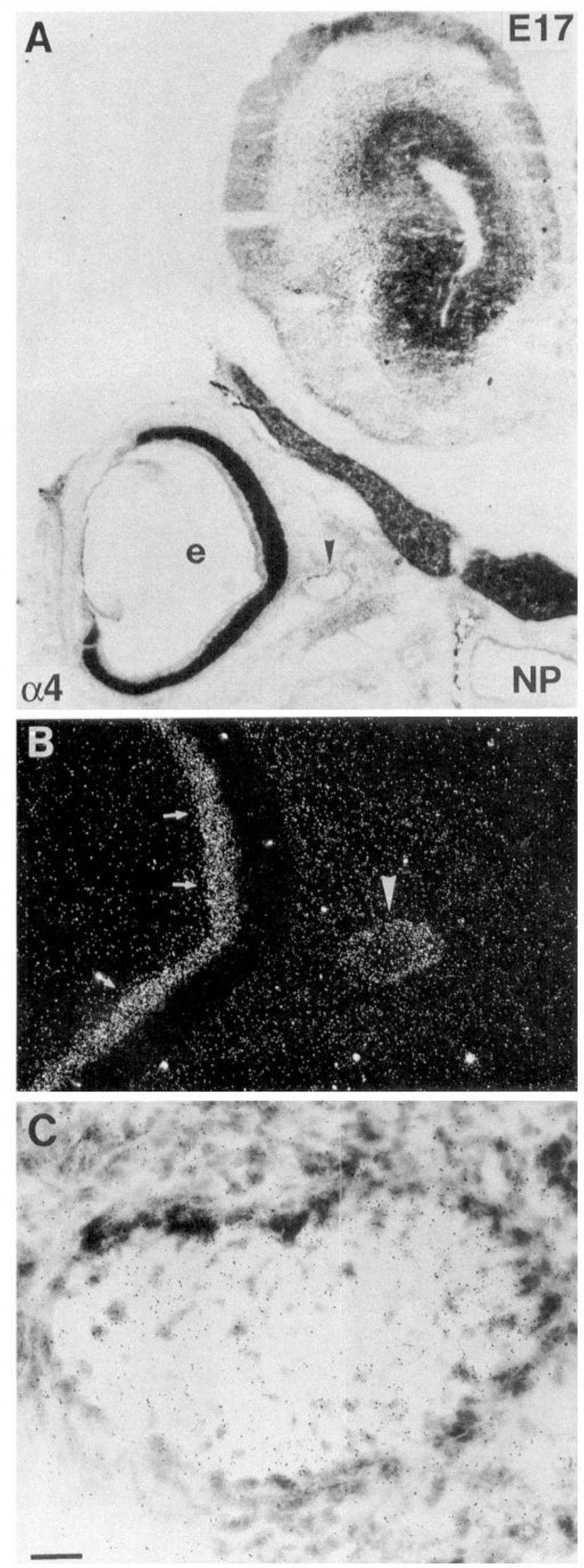

Table 5. Development of nAChR subunit mRNAs in the dorsal root ganglia

\begin{tabular}{lllll} 
& $\alpha 3$ & $\alpha 4$ & $\beta 2$ & $\beta 4$ \\
\hline E11 & +++ & ++ & ++ & ++ \\
E12 & +++ & +++ & +++ & ++ \\
E13 & +++ & +++ & +++ & ++ \\
E15 & + & - & +++ & + \\
E17 & + & - & +++ & - \\
P4 & + & - & +++ & -
\end{tabular}

Scores were attributed as follows: + , low level; ++ , intermediate level; +++ high level.

maturation of autonomic ganglia are largely postnatal in the rat (Pappano, 1977; Smolen and Raisman, 1980; Smith et al., 1981).

\section{Discussion}

Early expression of $n A C h R$ subunit $m R N A s$

In both CNS and PNS $\alpha 3, \alpha 4, \beta 2$, and $\beta 4$ nAChR subunit mRNAs appear very early, mostly at E11, a stage at which the first neurons differentiate from the central neuroepithelia and from primordia of peripheral ganglia.

The times of the last mitosis of neuronal precursor cells (Altman, 1992) and nAChR subunit mRNA appearance almost coincide in CNS and PNS (see, e.g., the temporally similar caudorostral gradient in the neuraxis). Accordingly, specific labeling was consistently observed in areas containing differentiated cells and not in neuroepithelia (Figs. 3, 8). These data suggest that high expression of nAChR mRNAs is rapidly achieved after the last mitosis in developing neurons.

Early expression of subunit mRNAs seems characteristic of $\mathrm{nAChR}$ as other ligand-gated ion channels become expressed somewhat later. For instance, $\mathrm{GABA}_{\mathrm{A}}$ receptor $\alpha 1-3,5-6, \beta 2-3$, and $\gamma 2$ subunit mRNAs were not detected in the rat brain until E14-15 (Laurie et al., 1992; Poulter et al., 1992, 1993) and NMDA receptor $\epsilon 1-4$ and $\gamma 1$ subunit mRNAs were not observed in the mouse brain until E13 (which corresponds to E14-15 in rat development) (Watanabe et al., 1992) and were very low in rat brain at E14 (Monyer et al., 1994).

In muscle, nAChRs accumulate before the arrival of the motor nerve ending (reviewed in Schuetze and Role, 1987; Changeux, 1991). This increase is accompanied by an elevation in subunit mRNA levels, a process under the control of tissue-specific transcription factors such as MyoD1 (Piette et al., 1990). It is thus possible that onset of neuronal $\mathrm{nAChR}$ subunit expression in most brain areas and ganglia is independent of innervation but, rather, is activated by molecules responsible for neuronal differentiation.

\section{Transient expression of $n A C h R$ subunit mRNAs}

Transient expression of one or more $n A C h R$ subunit mRNAs is observed in many CNS and PNS structures. Although in many $\leftarrow$

Figure 21. Bright-field $(A, C)$ and dark-field $(B)$ microphotographs of $\alpha 4$ mRNA labeling in the optic nerve in a coronal section of the rat head at E17. $B$ and $C$ are higher magnifications of the optic nerve in $A$. In $A$, the arrowhead points to the optic nerve. In $B$, the arrowhead and the arrows point to the optic nerve and the vitreal side of the retina, respectively. In $C$, note that the specific labeling overlies some cell bodies concentrated in the peripheral part of the nerve and not axonal bundles (which appear white in the picture) concentrated in its central part. Abbreviations: $e$, eye; $N P$, nasopharyngeal cavity. Scale bar, 25 $\mu \mathrm{m}$. 
Table 6. Development of nAChR subunit mRNAs in the ganglia associated with cranial and sympathetic nerves.

\begin{tabular}{|c|c|c|c|c|c|c|c|c|c|c|c|c|c|c|c|c|}
\hline \multirow[b]{2}{*}{ Days } & \multicolumn{4}{|c|}{ Trigeminal $\mathbf{g}$} & \multicolumn{4}{|c|}{ Sphenopalatine $g$} & \multicolumn{4}{|c|}{ Geniculate $\mathbf{g}$} & \multicolumn{4}{|c|}{ Vestibulo-cochlear gg } \\
\hline & $\alpha 3$ & $\alpha 4$ & $\beta \mathbf{2}$ & $\beta 4$ & $\alpha 3$ & $\alpha 4$ & $\beta 2$ & $\beta 4$ & $\alpha \mathbf{3}$ & $\alpha 4$ & $\beta 2$ & $\beta 4$ & $\alpha 3$ & $\alpha 4$ & $\beta 2$ & $\beta 4$ \\
\hline E11 & ++ & + & + & + & nd & nd & nd & nd & ++ & ++ & + & $++^{1}$ & ++ & ++ & + & $++^{1}$ \\
\hline E12 & +++ & ++ & ++ & ++ & nd & nd & nd & nd & - & ++ & ++ & $t^{1}$ & - & ++ & ++ & $+^{1}$ \\
\hline E13 & +++ & + & +++ & ++ & nd & nd & nd & nd & - & - & +++ & - & - & +++ & ++ & - \\
\hline E15 & + & - & $++t$ & + & +++ & - & ++ & +++ & - & - & +++ & - & - & ++ & +++ & - \\
\hline E17 & - & - & +++ & - & +++ & - & ++ & +++ & - & - & ++ & - & - & ++ & ++ & - \\
\hline E19 & - & - & +++ & - & +++ & - & ++ & +++ & - & - & +++ & - & - & ++ & ++ & - \\
\hline PO & - & - & +++ & - & $++t$ & - & ++ & ++ & nd & nd & nd & nd & - & ++ & ++ & - \\
\hline \multirow[t]{2}{*}{ P4 } & + & - & +++ & - & +++ & - & ++ & +++ & nd & nd & nd & nd & - & ++ & ++ & - \\
\hline & \multicolumn{4}{|c|}{ Otic g } & \multicolumn{4}{|c|}{ Superior IX g } & \multicolumn{4}{|c|}{ Inferior $\mathbf{L X} / \mathrm{X} g g$} & \multicolumn{4}{|c|}{ Sympathetic gg } \\
\hline Days & $\alpha 3$ & $\alpha 4$ & $\beta \mathbf{2}$ & $\beta 4$ & $\alpha 3$ & $\alpha 4$ & $\beta 2$ & $\beta 4$ & $\alpha 3$ & $\alpha 4$ & $\beta 2$ & $\beta 4$ & $\alpha 3$ & $\alpha 4$ & $\beta 2$ & $\beta 4$ \\
\hline E11 & nd & nd & nd & nd & +++ & ++ & + & $++^{2}$ & +++ & ++ & + & $++^{2}$ & nd & nd & nd & nd \\
\hline E12 & nd & nd & nd & nd & +++ & + & ++ & ++ & +++ & + & ++ & ++ & nd & nd & nd & nd \\
\hline E13 & nd & nd & nd & nd & ++ & + & ++ & + & +++ & + & ++ & + & nd & nd & nd & nd \\
\hline $\mathbf{E} 15$ & +++ & - & ++ & $++t$ & ++ & - & ++ & + & ++ & - & ++ & + & +++ & - & +++ & ++ \\
\hline E17 & +++ & - & ++ & +++ & - & - & ++ & - & ++ & - & ++ & ++ & +++ & - & +++ & +++ \\
\hline E19 & +++ & - & ++ & +++ & - & - & ++ & - & ++ & - & ++ & ++ & +++ & - & +++ & +++ \\
\hline PO & +++ & - & + & +++ & - & - & ++ & - & ++ & - & ++ & ++ & +++ & - & +++ & +++ \\
\hline P4 & +++ & - & + & +++ & - & - & +++ & - & ++ & - & +++ & ++ & +++ & - & +++ & +++ \\
\hline
\end{tabular}

At days E13, E15, and E17 both cervical and lumbar sympathetic ganglia were detected. At days E19, P0, and P4, only cervical sympathetic ganglia were detected. Abbreviations: g, ganglion; gg, ganglia; nd, not detected.

Notes: 'VII/VIII complex; 2 Superior and inferior IX and X ganglia were not distinguished.

instances several subunit mRNAs were detected in the same clusters of cells (see, e.g., Fig. 6), it could not be determined if nAChR subunit mRNAs in E11-13 embryos are coexpressed in the same cells or segregate in distinct cell populations. In the former case, repression of one or more subunits may cause a shift in the predominance of different nAChR isoforms or a switch in subunit composition from an embryonic to an adult form of the receptor, similar to what occurs in the developing muscle (Brehm and Henderson, 1988; Duclert et al., 1993).

On the other hand, $\beta 2$ mRNA is continuously and stably expressed in all structures studied, confirming previous data on widespread distribution of $\beta 2$ mRNA (Wada et al., 1989) and protein (Hill et al., 1993) in the adult rat CNS. Immunocytochemical studies at the electron microscopic level in CNS demonstratcd an cxccss of $\beta 2$ subunit protein in the cytoplasm relative to the plasma membrane, and it was suggested that the expression of $\beta 2$ subunit may be relatively unregulated in adult CNS (Hill et al., 1993). The present data further support this notion, as $\beta 2$ mRNA seems to be the least sensitive $n A C h R$ subunit transcript to developmental events.

Transient expression of other ligand-gated ion channel subunits has been observed in rodent CNS during prenatal and/or postnatal development (see, e.g., Zhang et al., 1991; Laurie et al., 1992; Poulter et al., 1992, 1993; Watanabe et al., 1992). However, the extreme precocity, widespread occurrence, and relative synchrony of $\mathrm{nAChR}$ subunit repression during early ontogeny seem characteristic of neuronal nAChR. This phenomenon may be similar to the evolution of muscle extrajunctional nAChR during endplate development, where several subunits are expressed initially and are subsequently repressed in extrajunctional areas by electrical activity after formation of functional motor endplates. Similarly, a widespread signal such as spontaneous electrical activity may serve as a candidate for $\mathrm{nAChR}$ subunit repression during neural development.

\section{Diversity of $n A C h R$ receptors during development}

A physiological role for $\mathrm{nAChR}$ expression during embryonic development requires that subunit mRNAs are translated into protein, transported, inserted into the cell membrane and that there exists cholinergic input able to activate them.

Although some authors have argued that development of nicotine binding in the rodent brain is mainly postnatal (Yamada et al., 1986; Fiedler et al., 1987; Kumar and Schliebs, 1992), other papers have documented high levels of nicotine binding during the embryonic period (Lichtensteiger, 1988; Zhang et al., 1990; Naeff et al., 1992). This discrepancy is likely to stem from meth- 

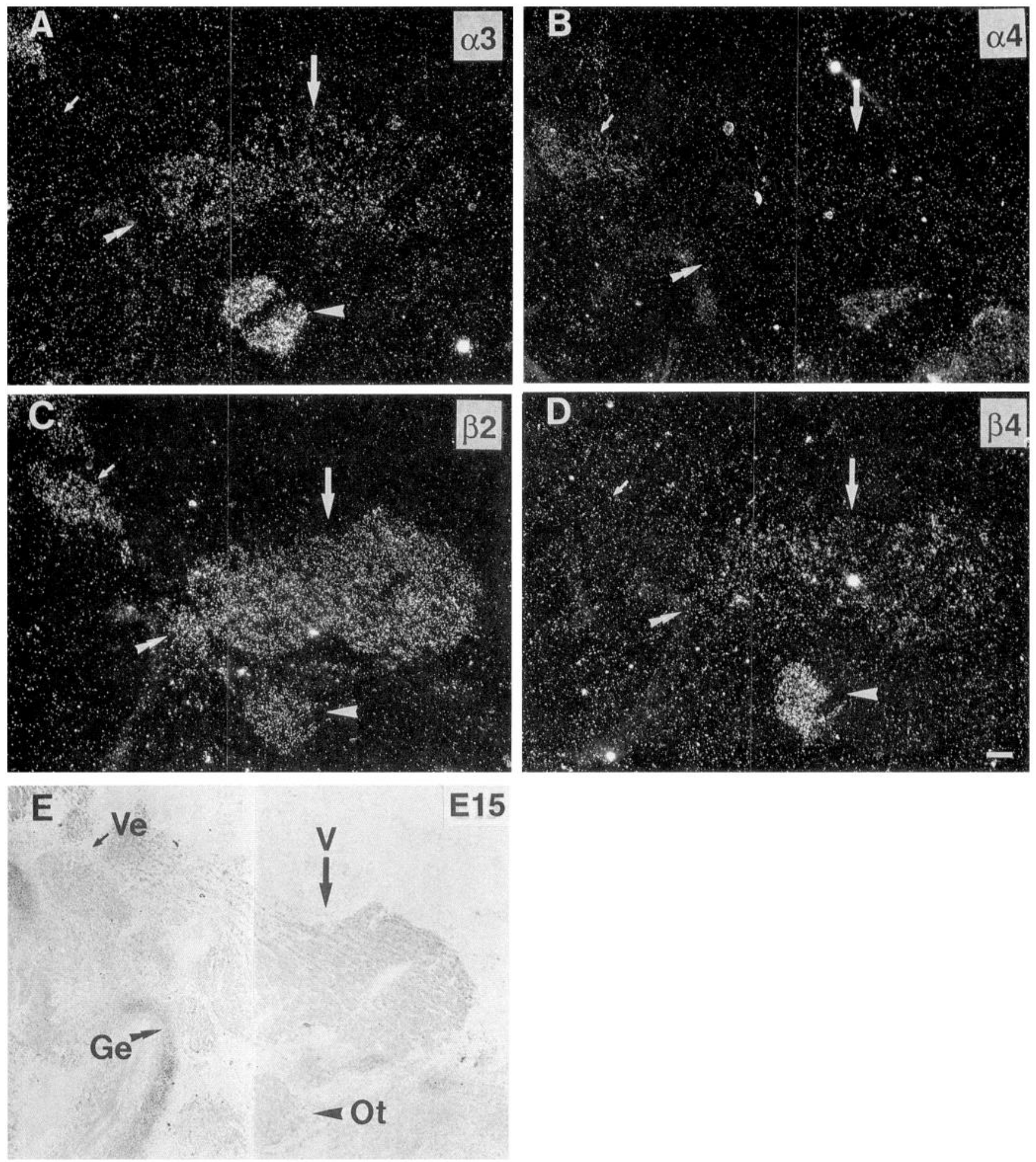

Figure 22. Dark-field microphotographs of emulsion autoradiograms showing nAChR subunit mRNAs in several cranial ganglia in sagittal sections of a E15 rat embryo. The nAChR subunit mRNA labeled is indicated in each panel. E shows toluidine blue staining. The big and small arrows point to the trigeminal $(V)$ and vestibular $(V e)$ ganglia, respectively, the arrowhead to the otic (Ot) ganglion, and the double arrowhead to the geniculate $(\mathrm{Ge})$ ganglion. Scale bar, $100 \mu \mathrm{m}$.

odological differences allowing preferential labeling of low or high affinity nicotine binding sites. Appearance of high affinity (10 nM) nicotine binding in the CNS follows a caudorostral gradient from spinal cord and caudal medulla oblongata (E11) to pons and midbrain (E12), diencephalon (E13), basal telenceph- alon (E14), and cortical subplate (E19) (Naeff et al., 1992). This gradient closely corresponds to that of the appearance of $\alpha 4$ subunit mRNA observed herein (see Table 2). $\beta 2$ expression is more precocious in rostral zones and, prior to the appearance of $\alpha 4$, either does not contribute to a functional receptor, or con- 

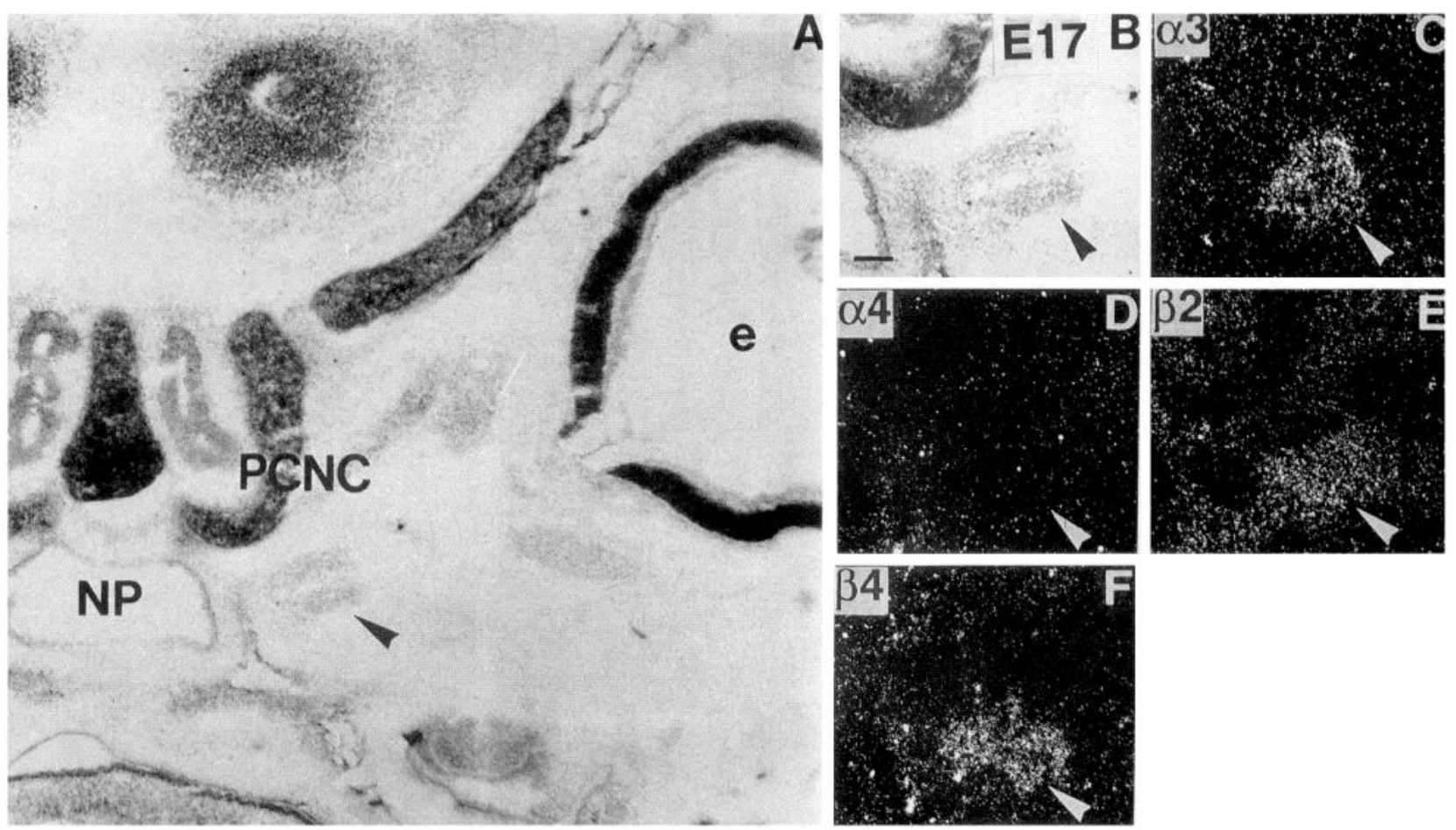

Figure 23. Dark-field microphotographs of emulsion autoradiograms showing nAChR subunit mRNAs in the sphenopalatine ganglion (arrowhead) in coronal sections of a E17 rat embryo. The nAChR subunit mRNA labeled is indicated in each panel. $A$ and $B$ show toluidine blue staining. In $A$, the arrowhead indicates the sphenopalatine ganglion magnified in $B$. Abbreviations: $e$, eye; $N P$, nasopharyngeal cavity; $P C N C$, posterior cupula of the nasal capsule. Scale bar, $100 \mu \mathrm{m}$.

stitutes a receptor which is not recognized in nicotine binding experiments (see below). A receptor formed by $\alpha 4$ and $\beta 2$ (and possibly also $\alpha 5$; see Conroy et al., 1992) is thus likely to be responsible for the high affinity nicotine binding observed in the prenatal development of most brain areas.

Throughout embryonic development, the distribution of $\alpha 3$ and $\beta 4$ subunit mRNAs display striking correspondence in most central and peripheral structures. $\beta 4$ mRNA was consistently detected in cerebral regions or ganglia where $\alpha 3$ was present. In addition, $\alpha 3$ was detected in some regions of the early (mesencephalon and telencephalon) and late (trigeminal and dorsal root ganglia) embryonic nervous system where $\beta 2$ rather than $\beta 4$ was present. Considering that the expression of $\alpha 3$ and $\beta 4$ subunits is highly restricted (e.g., cerebellar primordium, medial habenula, pineal gland, sympathetic and parasympathetic ganglia) these data strongly support the view that they form (possibly in combination with other subunits) a distinct neuronal nAChR subtype in the rat. This is in agreement with previous studies showing that a nAChR receptor formed by $\alpha 3, \alpha 5$, and $\beta 4$ mediates nicotinic transmission at the synapses of chick autonomic ganglia (Vernallis et al., 1993).

Based on the coincidence in regional distribution, receptors formed by other combinations of subunits may be functional during development, especially if complex combinations including more $\alpha$ and/or $\beta$ subunits are considered. A distinct possibility is the existence of a receptor formed by $\alpha 3$ and $\beta 2$ subunits (see above). However, when $\alpha 3$ and $\beta 2$ mRNAs are the only subunits detected, such as in the cerebral cortex at E13, no high affinity nicotine binding is detected (Naeff et al., 1992). This could be interpreted, inter alia, as a lack of translation or posttranslational processing of the subunits. Alternatively, this receptor may remain undetected by ${ }^{3} \mathrm{H}$-nicotine at the concentration used. In fact, in vitro $\alpha 4-\beta 2$ or $\alpha 3-\beta 4$ containing receptors have relatively high affinity for nicotine, whereas $\alpha 3-\beta 2$ combination has the lowest affinity for nicotine, though relatively high affinity for ACh (Luetje and Patrick, 1991).

Starting from late prenatal development, the combinations of nAChR subunits appear structure specific (Table 7). The analysis of other nicotinic subunits not considered here should further increase the number of region-specific isoforms. Mediation of nicotinic transmission in different classes of neural structures is thus likely to be based on a variety of specific isoforms of $\mathrm{nAChR}$. This heterogeneity opens up the possibility of a targeted pharmacology based on selective nicotinic drugs.

\section{$n A C h R$ receptors and cholinergic circuits during development}

The appearance of ChAT immunoreactivity (IR) and AChE activity in the CNS follows a caudorostral gradient (Armstrong et al., 1987; Schambra et al., 1989; Phelps et al., 1991). ChAT IR neurons are first visible in the spinal cord (somatic and then visceral motoneurons at E12-14) and, subsequently, in more rostral structures such as basal forebrain (E17-18). Cholinergic neurons are among the first to differentiate in the CNS regions studied and are thought to play a role in subsequent differentiation of other neuronal populations (Semba and Fibiger, 1988; Semba et al., 1988; Phelps et al., 1990; Barber et al., 1991).

Less is known regarding development of cholinergic innervation. Although the first ChAT IR cell bodies appear relatively early (see above), marked increases in ChAT IR nerve terminals and ChAT activity, especially in the forebrain, occur during the first postnatal weeks (Semba, 1992). However, other markers of cholinergic innervation, such as ACh levels (Coyle and Yama- 

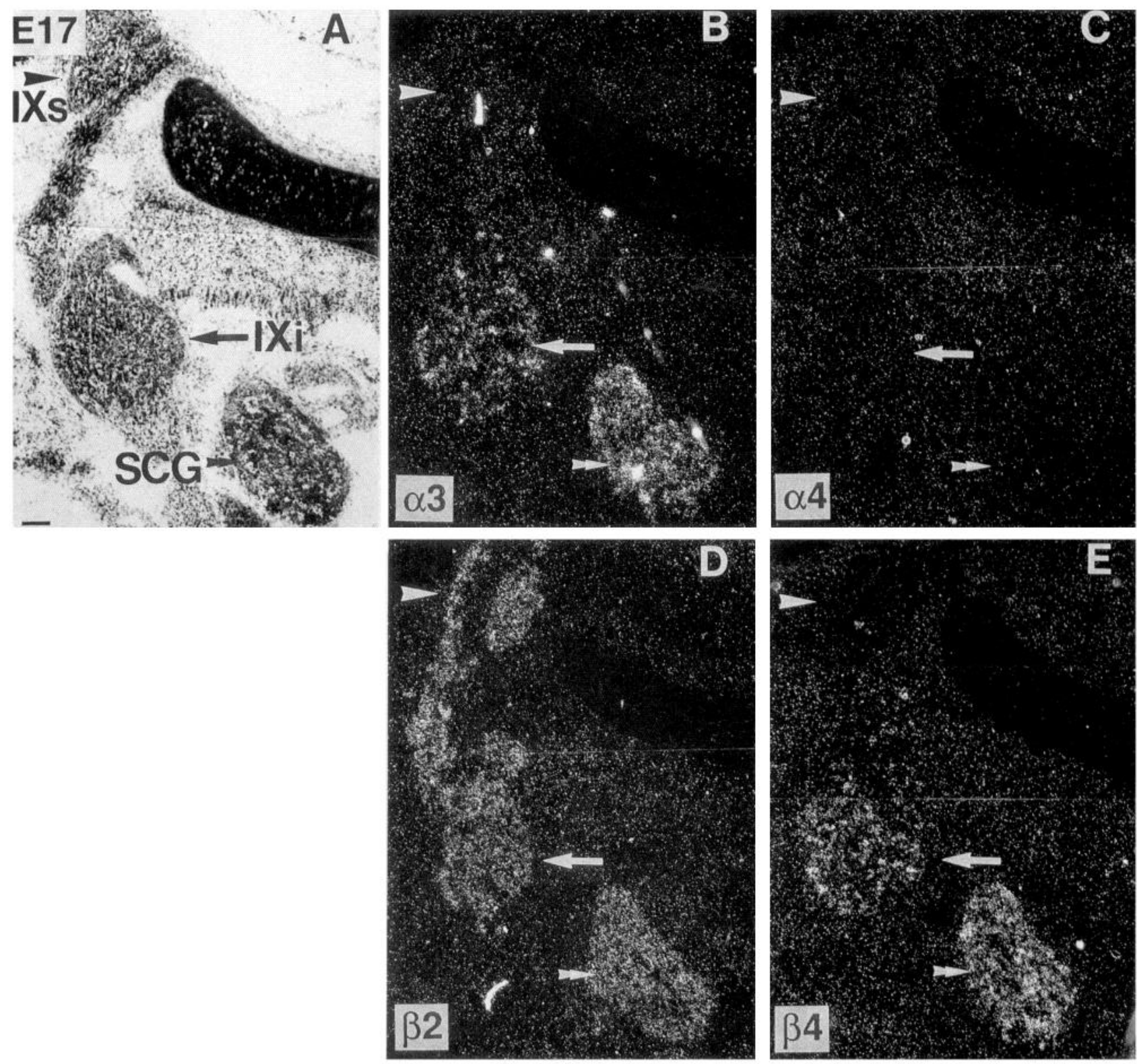

Figure 24. Dark-field microphotographs of emulsion autoradiograms showing nAChR subunit mRNAs in the superior (IXs, arrowhead) and inferior (IXi, arrow) glossopharyngeal ganglia and the superior cervical ganglion (SCG, double arrowhead) in coronal sections of a E17 rat embryo. The nAChR subunit mRNA labeled is indicated in each panel. A shows toluidine blue staining. Scale bar, $100 \mu \mathrm{m}$.

mura, 1976), AChE (Semba, 1992), NGF receptor (Koh and Loy, 1989) and choline uptake (a better marker of activity in cholinergic terminals than ChAT activity, Zahalka et al,, 1993), are more precocious. In particular, ${ }^{3} \mathrm{H}$-hemicolinium- 3 binding, a ligand for the high affinity choline transporter (Happe and Murrin, 1993), is very high in the prenatal brain, suggesting that the limited number of prenatal cholinergic terminals may have higher activity than those of the adult (Zahalka et al., 1993).

The presence of cholinergic circuits in embryonic neural tissue suggests a role for $\mathrm{ACh}$ and $\mathrm{nAChRs}$ in the development of rat CNS and PNS (Lauder, 1993). In vitro, nicotinic antagonists block the ACh-induced inhibition of neurite outgrowth from rat retinal ganglion cells (Lipton et al., 1988) and nicotine (or ACh) causes neurite retraction in chick ciliary ganglion cells (Pugh and Berg, 1994). Moreover, ACh, through neuronal nAChRs, is a chemoattractant for growth cones of Xenopus spinal neurons
(Zheng et al., 1994). Much evidence has accumulated on the developmental effects of prenatal or neonatal in vivo manipulation of ACh systems and nAChRs (Hagino and Lee, 1985; Slotkin et al., 1987; Navarro et al., 1989; Nordberg et al., 1991). These effects include decrease in cortical cell number, blunted maturation of cortical cholinergic systems and upregulation of nicotine binding sites (Wonnacott, 1990). Our data documenting high levels of nAChR subunit mRNAs in embryonic CNS and PNS further support the notion of a morphogenetic role of ACh and $\mathrm{nAChRs}$ in the prenatal period.

\section{References}

Altman J (1992) The early stages of nervous system development: neurogenesis and neuronal migration. In: Handbook of chemical neuroanatomy, Vol 10, Ontogeny of transmitters and peptides in the CNS (Björklund A, Hökfelt T, Tohyama M, eds), pp 1-31. Amsterdam: Elsevier. 
Table 7. Developmental changes in nAChR subunit expression

\begin{tabular}{llll} 
& $\begin{array}{l}\text { Early embryonic } \\
\text { period }\end{array}$ & $\begin{array}{l}\text { Late embryonic/early } \\
\text { postnatal periods }\end{array}$ & $\begin{array}{l}\text { Main types } \\
\text { of neurons }\end{array}$ \\
\hline Caudal brain & $\alpha 3-\alpha 4-\beta 2-(\beta 4)$ & $\alpha 4-\beta 2$ & \\
Rostral brain & $\alpha 3-\alpha 4-\beta 2$ & $\alpha 4-\beta 2^{b}$ & \\
Spinal cord & $\alpha 3-\alpha 4-\beta 2-\beta 4$ & $(\alpha 4)-\beta 2$ & $(\mathrm{vi})$ \\
Retina & $\alpha 3-\alpha 4-\beta 2-\beta 4$ & $\alpha 3-\alpha 4-\beta 2-(\beta 4)$ & (SS, VSc) \\
Dorsal root ganglia & $\alpha 3-\alpha 4-\beta 2-\beta 4$ & $(\alpha 3)-\beta 2$ & Tr (SS, VS ) \\
Cranial nerve ganglia & $\alpha 3-(\alpha 4)-\beta 2-(\beta 4)$ & $(\alpha 3)-\beta 2$ & $\mathrm{Ge}(\mathrm{SS}, \mathrm{Gu}), \mathrm{IXs}(\mathrm{SS}, \mathrm{Gu})$ \\
& $\alpha 3-(\alpha 4)-\beta 2-(\beta 4)$ & $\beta 2$ & $\mathrm{SP}$ (PM), Ot (PM) \\
& $\alpha 3-\beta 2-\beta 4$ & $\alpha 3-\beta 2-\beta 4$ & $\mathrm{IXi}(\mathrm{VS}), \mathrm{Xi}(\mathrm{VS})$ \\
& $\alpha 3-(\alpha 4)-\beta 2-\beta 4$ & $\alpha 3-\beta 2-\beta 4$ & $\mathrm{Co}$ (Au), Ve (Eq) \\
Sympathetic ganglia & $\alpha 4-\beta 2$ & $\alpha 4-\beta 2$ & (SM) \\
Pineal gland & $\alpha 3-\beta 2-\beta 4$ & $\alpha 3-\beta 2-\beta 4$ &
\end{tabular}

Values within brackets indicate low levels of the transcript. Abbreviations: IXi,s, inferior and superior ganglia of the glossophiaryngeal (IX) nerve; Xi, inferior ganglion of the vagus $(X)$ nerve; Au, auditory; Co, cochlear ganglion (VIII nerve); Ge, geniculate ganglion (VII nerve); Gu, gustatory; Ot, otic ganglion (IX nerve); PM, parasympathetic motor; SM, sympathetic motor; SP, sphenopalatine ganglion (VII nerve); SS, somatic sensory; Tr, trigeminal ganglion (V nerve); Ve, vestibular ganglion (VIII nerve); Vi, visual; VS, visceral sensory.

"Only in the case of ganglionic cells.

${ }^{b}$ With the exception of medial habenula which expresses $\alpha 3, \alpha 4, \beta 2$ and $\beta 4$ subunits and of some telencephalic areas, like the olfactory bulb and the caudate-putamen which express only $\beta 2$.

Trigeminal ganglion and dorsal root ganglia mainly contain somatic sensory afferents from the skin of the face and the rest of the body, respectively, but also some visceral sensory afferents from the buccal mucosa and internal organs, respectively.

Altman J, Bayer S (1978) Development of the diencephalon in the rat. I. Autoradiographic study of the time of origin and settling patterns of neurons of the hypothalamus. J Comp Neurol 182:945-972.

Altman J, Bayer S (1979a) Development of the diencephalon in the rat. IV. Quantitative study of the time of origin of neurons and the internuclear chronological gradients in the thalamus. J Comp Neurol 188:455-472.

Altman J, Bayer S (1979b) Development of the diencephalon in the rat. V. Thymidine-radiographic observations on internuclear and intranuclear gradients in the thalamus. J Comp Neurol 188:473-500.

Altman J, Bayer S (1982) Development of the cranial nerve ganglia and related nuclei in the rat. Adv Anat Embryol Cell Biol 74.

Anand R, Conroy WG, Schoepfer R, Whiting P, Lindstrom P (1991) Neuronal nicotinic acetylcholine receptors expressed in Xenopus oocytes have a pentameric quaternary structure. J Biol Chem 266: 11192-11198.

Angevine JB, Sidman RL (1961) Autoradiographic study of cell migration during histogenesis of cerebral cortex in the mouse. Nature 192:766-768.

Armstrong DM, Bruce G, Hersh LB, Gage FH (1987) Development of cholinergic neurons in the septal/diagonal band complex of the rat. Dev Brain Res 36:249-256.

Barber RP, Phelps PE, Vaughn JE (1991) Generation patterns of immunocytochemically identified cholinergic neurons at autonomic levels of the rat spinal cord. J Comp Neurol 311:509-519.

Boulter J, Evans K, Goldman D, Martin G, Treco D, Heinemann S, Patrick J (1986) Isolation of a cDNA clone coding for a possible neural nicotinic acetylcholine receptor $\alpha$-subunit. Nature 319:368374.

Bowers CW, Dahm LM, Zigmond RE (1984) The number and distribution of sympathetic neurons that innervate the rat pineal gland. Neuroscience 13:87-96.

Brehm P, Henderson L (1988) Regulation of acetylcholine receptor function during development of skeletal muscle. Dev Biol 129:1-11.

Changeux JP (1991) Compartmentalized transcription of acetylcholine receptor genes during motor endplate epigenesis. New Biol 3:413429.

Cockcroft VB, Osguthorpe DJ, Barnard EA, Friday AE, Lunt GG (1992) Ligand-gated channels. Ilomology and diversity. Mol Neurobiol 4:129-169.

Colello RJ, Guillery RW (1992) Observations on the early development of the optic nerve and tract of the mouse. J Comp Neurol 317: $357-378$.
Conroy W, Vernallis AB, Berg DK (1992) The $\alpha 5$ gene product assembles with multiple acetylcholine receptor subunits to form distinctive receptor subtypes in brain. Neuron 9:679-691

Cooper E, Couturier S, Ballivet M (1991) Pentameric structure and subunit stoichiometry of a neuronal nicotinic acetylcholine receptor. Nature 350:235-238.

Corriveau RA, Berg D (1993) Coexpression of multiple acetylcholine receptor genes in neurons: quantification of transcripts during development. J Neurosci 13:2662-2671.

Coyle JT, Yamamura HI (1976) Neurochemical aspects of the ontogenesis of cholinergic neurons in rat brain. Brain Res 118:429-440.

Daubas P, Devillers-Thiéry A, Geoffroy B, Martinez S, Bessis A, Changeux J-P (1990) Differential expression of the neuronal acetylcholine receptor $\alpha 2$ subunit gene during chick brain development. Neuron 5:49-60.

Deneris ES, Connolly J, Boulter J, Wada E, Wada K, Swanson LW, Patrick J, Heinemann S (1988) Primary structure and expression of $\beta 2$ : a novel subunit of neuronal nicotinic acetylcholine receptors. Neuron 1:45-54.

Dineley-Miller K, Patrick J (1992) Gene transcripts for the nicotinic acetylcholine receptor subunit beta4 are distributed in multiple areas of the rat central nervous system. Mol Brain Res 16:339-344.

Duclert A, Savatier N, Changeux J-P (1993) An 83-nucleotide promoter of the acetylcholine receptor $\epsilon$-subunit gene confers preferential synaptic expression in mouse muscle. Proc Natl Acad Sci USA 90:3043-3047.

Duvoisin RM, Deneris ES, Patrick J, Heinemann S (1989) The func. tional diversity of the neuronal nicotinic acetylcholine receptors is increased by a novel subunit: $\beta 4$. Neuron 3:487-496.

Fiedler EP, Marks MJ, Collins AC (1987) Postnatal development of cholinergic enzymes and receptors in mouse brain. J Neurochem 49: 983-990.

Flores CM, Rogers SW, Pabreza LA, Wolfe BB, Kellar KJ (1992) A subtype of nicotinic cholinergic receptor in rat brain is comprised of alpha4 and beta 2 subunits and is up-regulated by chronic nicotine treatment. Mol Pharmacol 41:31-37.

Galzi JL, Changeux JP (1992) The nicotinic acetylcholine receptor, a model of ligand-gated channels. Annu Rev Pharmacol 31:37--72.

Goldman D, Deneris E, Luyten W, Kochhar A, Patrick J, Heinemann J (1987) Members of a nicotinic acetylcholine receptor gene family are expressed in different regions of the mammalian central nervous system. Cell 48:965-973. 
Gottesfeld Z (1983) Origin and distribution of noradrenergic innervation in the habenula: a neurochemical study. Brain Res 275:299-304.

Hagino N, Lee JW (1985) Effect of maternal nicotine on the development of sites for $\left[{ }^{3} \mathrm{H}\right]$ nicotine binding in the fetal brain. Int $\mathrm{J}$ Dev Neurosci 3:567-571.

Halvorsen SW, Berg DK (1990) Subunit composition of nicotinic acetylcholine receptors from chick ciliary ganglia. J Neurosci 10:17111718.

Happe HK, Murrin LC (1993) High-affinity choline transport sites: use of $\left[{ }^{3} \mathrm{H}\right]$ hemicoliniun-3 as a quantitative marker. J Neurochem 60: 1191-1201

Hill JA, Zoli M, Bourgeois JP, Changeux JP (1993). Immunocytochemical localization of a neuronal nicotinic receptor: the $\beta 2$ subunit. $J$ Neurosci 13:1551-1568.

Hoover F, Goldman D (1992) Temporally correlated expression of $\mathrm{nAChR}$ genes during development of the mammalian retina. Exp Eye Res 54:561-571

Ishii K, Oda Y, Ichikawa T, Deguchi T (1990) Complementary DNAs for choline acetyltransferase from spinal cords of rat and mouse: nucleotide sequences, expression in mammalian cells, and in situ hybridization. Mol Brain Res 7:151-159.

Kaufman MH (1992) The atlas of mouse development. San Diego: Academic.

Koh S, Loy R (1989) Localization and development of nerve growth factor-sensitive rat basal forebrain neurons and their afferent projections to hippocampus and neocortex. J Neurosci 9:2999-3018.

Kumar A, Schliebs R (1992) Postnatal laminar development of cholinergic receptors, protein kinase $\mathrm{C}$ and dihydropyridine-sensitive calcium antagonist binding in rat visual cortex. Effect of visual deprivation. Int J Dev Neurosci 10:491-504.

Lauder JM (1993) Neurotransmitters as growth regulatory signals: role of receptors and second messengers. Trends Neurosci 16:233-240.

Laurie DJ, Wisden W, Seeburg PH (1992) The distribution of thirteen $\mathrm{GABA}_{\mathrm{A}}$ receptor subunit mRNAs in the rat brain. III. Embryonic and postnatal development. J Neurosci 12:4151-4172.

Lichtensteiger W, Ribary U, Schlumpf M, Odermatt B, Widmer HR (1988) Prenatal adverse effects of nicotine on the developing brain. Prog Brain Res 72:137-157.

Lipton SA, Frosch MP, Phillips MD, Tauck DL, Aizenman E (1988) Nicotinic antagonists enhance process outgrowth by rat retinal ganglion cells in culture. Science 239:1293-1296.

Listerud M, Brussaard AB, Devay P, Colman DR, Role LW (1991) Functional contribution of neuronal AChR subunits revealed by antisense oligonucleotides. Science 254:1518-1521.

Luetje CW, Patrick J (1991) Both $\alpha$ - and $\beta$-subunits contribute to the agonist sensitivity of neuronal nicotinic acetylcholine receptors. J Neurosci 11:837-845.

Margiotta JF, Gurantz D (1989) Changes in the number, function and regulation of nicotinic acetylcholine receptors during neuronal development. Dev Biol 135:326-339.

Matter JM, Matter-Sadzinski L, Ballivet M (1990) Expression of neuronal acetylcholine receptor genes in the developing chick visual system. EMBO J 9:1021-1026.

Monyer H, Burnashev N, Laurie DJ, Sakmann B, Seeburg PH (1994) Developmental and regional expression in the rat brain and functional properties of four NMDA receptors. Neuron 12:529-540.

Moss BL, Schuetze SM, Role LW (1989) Functional properties and developmental regulation of nicotinic acetylcholine receptors on embryonic chicken sympathetic neurons. Neuron 3:597-607.

Mulle C, Vidal C, Benoit P, Changeux J-P (1991) Existence of different subtypes of nicotinic acetylcholine receptors in the rat habenulo-interpeduncular system. J Neurosci 11:2588-2597.

Naeff B, Schlumpf M, Lichtensteiger W (1992) Pre- and postnatal development of high-affinity $\left[{ }^{3} \mathrm{H}\right]$ nicotine binding sites in rat brain regions: an autoradiographic study. Dev Brain Res 68:163-174.

Navarro HA, Seidler FJ, Eylers JP, Baker FE, Dobbins SS, Lappi SE, Slotkin TA (1989) Effects of prenatal nicotine exposure on development of central and peripheral cholinergic neurotransmitter systems. J Pharmacol Exp Ther 251:894-900.

Nordberg A, Zhang XA, Frederikson A, Erikson P (1991) Neonatal nicotine exposure induces permanent changes in brain nicotinic receptors and behaviour in adult mice. Dev Brain Res 62:23-31.

Pappano AJ (1977) Ontogenic development of autonomic neuroeffector transmission and transmitter reactivity in embryonic and fetal hearts. Pharmacol Rev 29:3-33.
Paxinos G, Watson C (1986) The rat brain in stereotaxic coordinates. New York: Academic.

Paxinos G, Törk I, Tecott LH, Valentine KL (1991) The atlas of developing rat brain. San Diego: Academic

Phelps PE, Brennan LA, Vaughn JE (1990) Generation patterns of immunocytochemically identified cholinergic neurons in rat brainstem. Dev Brain Res 56:63-74.

Phelps PE, Barber PB, Vaughn JE (1991) Embryonic development of choline acetyltransferase in thoracic spinal motor neurons: somatic and autonomic neurons may be derived from a common cellular group. J Comp Neurol 307:77-86.

Piette J, Bessereau JL, Huchet M, Changeux JP (1990) Two adjacent MyoD1-binding sites regulate expression of the acetylcholine receptor $\alpha$-subunit gene. Nature 345:353-355.

Poulter MO, Barker JL, O'Carroll AM, Lolait SJ, Mahan LC (1992) Differential expression of $\mathrm{GABA}_{\mathrm{A}}$ receptor $\alpha$-subunit mRNAs in the developing rat CNS. J Neurosci 12:2888-2900.

Poulter MO, Barker JL, O'Carroll AM, Lolait SL, Mahan LC (1993) Co-existent expression of $\mathrm{GABA}_{\mathrm{A}}$ receptor $\beta 2, \beta 3$ and $\gamma 2$ subunit messenger RNAs during embryogenesis and early postnatal development of the rat central nervous system. Neuroscience 53:10191033.

Pugh PC, Berg DK (1994) Neuronal acetylcholine receptors that bind $\alpha$-bungarotoxin mediate neurite retraction in a calcium-dependent manner. J Neurosci 14:889-896.

Reiter R (1989) The pineal gland. In: Endocrinology (DeGroot LJ, ed). Philadelphia: Saunders.

Role LW (1988) Neural regulation of acetylcholine sensitivity in embryonic sympathetic neurons. Proc Natl Acad Sci USA 85:28252829.

Role LW (1992) Diversity in primary structure and function of neuronal nicotinic acetylcholine receptor channels. Curr Opinion Neurobiol 2:254-262.

Salpeter M, Loring RH (1985) Nicotinic acetylcholine receptors in vertebrate muscle: properties, distribution and neural control. Prog Neurobiol 25:297-325.

Sargent PB (1993) The diversity of neuronal nicotinic acetylcholine receptors. Annu Rev Neurosci 16:403-443.

Schambra UB, Sulik KK, Petrusz P, Lauder JM (1989) Ontogeny of cholinergic neurons in the mouse forebrain. J Comp Neurol 288:101122.

Schambra UB, Lauder JM, Silver J (1992) Atlas of the prenatal mouse brain. San Diego: Academic.

Schuetze SM, Role LW (1987) Developmental regulation of nicotinic acetylcholine receptors. Annu Rev Neurosci 10:403-457.

Semba K (1992) Development of central cholinergic neurons. In: Handbook of chemical neuroanatomy, Vol 10, Ontogeny of transmitters and peptides in the CNS (Björklund A, Hökfelt T, Tohyama M, eds), pp 33-62. Amsterdam: Elsevier.

Semba K, Fibiger HC (1988) Time of origin of cholinergic neurons in the rat basal forebrain. J Comp Neurol 269:87-95.

Semba K, Vincent SR, Fibiger HC (1988) Different times of origin of choline acetyltransferase- and somatostatine-immunoreactive neurons in the rat striatum. J Neurosci 8:3937-3944.

Slotkin TA, Orband-Miller L, Queen KL (1987) Development of $\left[{ }^{3} \mathrm{H}\right]$ nicotine binding sites in brain regions of rats exposed to nicotine prenatally via maternal injections or infusions. J Pharmacol Exp Ther 242:232-237.

Smith PG, Mills E, Slotkin TA (1981) Maturation of sympathetic neu rotransmission in the efferent pathway to the rat heart: ultrastructural analysis of ganglionic synaptogenesis in euthyroid and hyperthyroid neonales. Neuroscience 6:911-918.

Smolen A, Raisman G (1980) Synapse formation in the rat superior cervical ganglion during normal development and after neonatal deafferentation. Brain Res 181:315-323.

Vernallis AB, Conroy WG, Berg DK (1993) Neurons assemble acetylcholine receptors with as many as three kinds of subunits and can segregate subunits among receptor subtypes. Neuron 10:451-464.

Wada E, Wada K, Boulter J, Deneris E, Heinemann S, Patrick J, Swanson LW (1989) Distribution of alpha2, alpha3, alpha4, and bcta2 neuronal nicotinic receptor subunit mRNAs in the central nervous system: a hybridization histochemical study in the rat. J Comp Neurol 284:314-335.

Watanabe M, Inoue Y, Sakimura K, Mishina M (1992) Developmental 
changes in distribution of NMDA receptor channel subunit mRNAs. Neuroreport 3:1138-1140.

Whiting PJ, Schoepfer R, Conroy WG, Gore MJ, Keyser KT, Shimasaki S, Esch F, Lindstrom J (1991) Expression of nicotinic acetylcholine receptor subtypes in brain and retina. Mol Brain Res 10:61-70.

Wonnacott S (1990) The paradox of nicotinic acetylcholine receptor up-regulation by nicotine. Trends Pharmacol Sci 11:216-219.

Yamada S, Kagawa Y, Isogai M, Takayanagi N, Hayashi E (1986) Ontogenesis of nicotinic acetylcholine receptors and presynaptic cholinergic neurons in mammalian brain. Life Sci 38:637-644.

Young WS, Bonner TI, Brann MR (1986) Mesencephalic dopamine neurons regulate the expression of neuropeptide mRNAs in the rat forebrain. Proc Natl Acad Sci USA 83:9827-9831
Zahalka EA, Seidler FJ, Lappi SE, Yanai J, Slotkin TA (1993) Differential development of cholinergic nerve terminal markers in rat brain regions: implications for nerve terminal density, impulse activity and specific gene expression. Brain Res 601:221-229.

Zhang JH, Sato M, Tohyama M (1991) Different postnatal development profiles of neurons containing distinct $\mathrm{GABA}_{\mathrm{A}}$ receptor $\beta$ subunit mRNAs ( $\beta 1, \beta 2$ and $\beta 3$ ) in the rat forebrain. J Comp Ncurol 308:586-613.

Zhang XA, Wahlstrom G, Nordberg A (1990) Influence of development and aging on nicotinic receptor subtypes in rodent brain. Int $\mathbf{J}$ Dev Neurosci 8:715-721.

Zheng JQ, Felder M, Connor JA, Poo M-m (1994) Turning of nerve growth cones induced by neurotransmitters. Nature 368:140-144. 